\title{
A!
}

This is an electronic reprint of the original article.

This reprint may differ from the original in pagination and typographic detail.

Kirjavainen, Senni ; Hölttä-Otto, Katja

\section{Deconstruction of Idea Generation Methods Into a Framework of Creativity Mechanisms}

Published in:

Journal of Mechanical Design

DOI:

$10.1115 / 1.4048539$

E-pub ahead of print: 10/11/2020

Document Version

Peer reviewed version

Published under the following license:

CC BY

Please cite the original version:

Kirjavainen, S., \& Hölttä-Otto, K. (2020). Deconstruction of Idea Generation Methods Into a Framework of Creativity Mechanisms. Journal of Mechanical Design, 143(3), [031401]. https://doi.org/10.1115/1.4048539

This material is protected by copyright and other intellectual property rights, and duplication or sale of all or part of any of the repository collections is not permitted, except that material may be duplicated by you for your research use or educational purposes in electronic or print form. You must obtain permission for any other use. Electronic or print copies may not be offered, whether for sale or otherwise to anyone who is not an authorised user. 


\title{
Deconstruction of Idea Generation Methods Into a Framework of Creativity Mechanisms
}

\author{
Senni Kirjavainen, first author \\ Design Factory, Aalto University \\ P.O. Box 17700, FI-00076 AALTO, FINLAND \\ senni.kirjavainen@aalto.fi \\ Katja Hölttä-Otto, second author \\ Design Factory \& Department of Mechanical Engineering \\ P.O. Box 17700, FI-00076 AALTO, FINLAND \\ katja.holtta-otto@aalto.fi \\ ASME Member
}

\begin{abstract}
Creative ideas are a central part of design thinking, whether solving engineering problems, generating interesting art, as well as developing successful products and innovations. Idea generation methods are a well-researched topic, there is significant research that focuses on specific idea generation methods and how they perform. Further, several method classifications have been suggested to help understand the cognitive mechanisms involved in creative ideation as well as the differences between methods. Yet, the discourse is usually on which ideation method outperforms another or how to improve an ideation method rather than the elements, rules, constraints, and activities that comprise ideation methods. In this study 88 well-documented idea generation methods are reviewed and analyzed. We find all analyzed methods consist of 25 basic mechanisms. The mechanisms are discussed and classified into idea promoting and implementation mechanisms. We suggest that rather than focusing research only on methods, there should be a parallel track of research on these mechanisms and their interactions to help increase our understanding of creativity methods, add understanding for practitioners on how to get the best advantages out of creativity methods and lastly improve the way that practical creativity is approached in education.
\end{abstract}




\section{INTRODUCTION}

In order to change the status quo, solve problems, and develop new products, it is essential to generate novel ideas. There are numerous idea generation methods that can help advance the creation of innovative ideas. These methods vary from approximate guidelines and small adjustments in one's behavior to carefully facilitated processes and holistic approaches. In the context of design and engineering activities idea generation usually involves communicating new thoughts and possibilities in a textual, visual, verbal, or tangible form. Generally, idea generation methods work by helping to increase the amount of new ideas, by removing mental blocks that restrain our imagination or widening the scope of search [1]. Designers are also known to tap to existing knowledge and solutions to generate new ideas and possibilities [2] and idea generation methods can also support this process. In the end, the goal of using idea generation methods is to enhance or facilitate individual or team creativity, in other words help in reaching original and useful ideas - those two qualities being the standard definition of creativity [3]. The authors have noticed though, that when studying, teaching, and using creativity methods, the methods are essentially just compilations of recurring elements that dictate how the method is carried out, and these differences in compilations have an effect on our abilities to produce novel ideas in a wide variety.

There is a significant amount of research at the methodological level focusing on the effectiveness and outcomes of idea generation methods [e.g. 4 - 6]. Studies often compare only a few methods against each other, which complicates forming a broader understanding and comparing the vast variety of existing idea generation methods. To 
get past the dilemma of comparing methods against each other, a stream of studies can be compiled with focus on only certain elements of the methods, aiming at finding out if these elements affect idea generation positively. For example, studies have demonstrated the effects that empathic priming [7] or the use of analogies [8] have on the outcomes of idea generation methods, or similarly whether e.g. gallery viewing or rotating ideas sparks more new ideas [9].

Such previous studies have provided valuable knowledge on idea generation and some of the underlying elements that affect idea generation positively. In this paper we aim at recognizing the multitude of these elements - that we from now on call mechanisms - and generating a suggested framework of mechanisms that comprise idea generation methods. Therefore, the main aim of the current study is to add understanding and theoretical knowledge of idea generation methods by taking a look beyond the methods. This paper contributes to research and teaching as well as to practice. Focusing on mechanisms instead of combinations of mechanisms in the form of idea generation methods, we aim at improving the comparability of research on idea generation. In addition to this, we hope that through adding understanding of the mechanisms that idea generation methods are comprised of, practitioners would be able to modify existing methods according to their needs or even create novel methods for idea generation. This understanding would also benefit engineering and design educators, when new generations of practitioners are taught problem-solving skills. Further, previous research has shown that understanding the components of idea generation could explain why some idea generation methods prove more effective than 
others [5]. This paper presents a study where idea generation methods are searched in literature and their instructions are coded and analyzed to find the comprising mechanisms. Our analysis results in a framework of mechanisms that we suggest be the building blocks of idea generation methods.

\section{BACKGROUND}

A plethora of idea generation methods can be found in books, websites and the academic literature. The exact amount of idea generation methods is debatable and depends on how one defines an idea generation method. Takahashi [10] claims to have identified as many as 300 techniques for solving creative problems, and a variety of books written for practitioners [e.g. 11 - 13] present roughly one hundred methods for design or problem solving. Some of these methods, however, are designed for phases before or following the idea generation phase. For example, De Bono's [14] PMI (plus, minus, interesting) model is an "attention directing tool" used for making sure all aspects of an issue are considered before making decisions, thus it helps to understand a problem but is not targeted for generating ideas for solving the chosen problem. Further, some methods are structured processes and some are merely tools, pieces of advice or small additions to other methods that can help in triggering ideas [15] or broaden the line of thought. There is a wide range of previous research on idea generation methods, which this study builds on. We will give a short overview of how previous research has clarified idea generation methods and mechanisms.

\subsection{Idea generation method classifications}

MD-20-1399, Kirjavainen 4 
Although most studies look into a specific method or a specific mechanism such as incubation [e.g.16] or modality [e.g. 9], there are also studies that create a more holistic understanding of idea generation methods. The attempt of understanding idea generation methods has been of interest in engineering design, design research, cognitive science, and management science. To form a deeper understanding of the logic of generating ideas, scientists across these fields have classified idea generation in several ways, including for example from the perspective of active ingredients [15], through identifying components of idea generation methods and measuring their effectiveness [e.g. 5, 6], through stages of problem solving process [17], and through the cognitive thinking process of how the problems are solved [e.g. 10].

There are also previous studies on classifying idea generation mechanisms. The closest previous work to the current study is a set of studies, where the aim has been to create a means to measure the effectiveness of different components in promoting idea generation $[5,6]$. Other studies aim to understand practices of creative professionals [17] or to understand the role that creative practice can have in the success of a business. Despite the goals of the studies perhaps being unrelated, they have nonetheless produced valuable knowledge on idea generation mechanisms. For example, it has been suggested that some idea generation mechanisms are stronger, easier to manipulate, or more complex in terms of interaction than others [6]. In a similar study Vargas-Hernandez et al. [6] suggest grouping mechanisms into idea generation principles and components, the principles being higher-level actions such as frame shifting and more fundamental than components such as incubation. 
As said, one way in which idea generation methods have been classified is through the cognitive thinking process. This is not surprising, as a big part of creativity research focuses on the cognitive side of creativity and most previous studies at least touch upon cognition. One previous way of classifying idea generation methods has been a division into methods of 'free-association', 'forced relationship', 'analytical methods' and 'eclectic methods' [18]. Another categorization divides idea generation methods into divergent and convergent techniques, the combinations of these two and also attitudinal techniques such as 'dramatic' or 'meditative' techniques [10]. Smith [15] suggests that we need to first understand the essential mechanisms of idea generation methods and their connections to cognitive processes to understand how idea generation methods work. A method must trigger our cognition to result in new ideas. This is achieved through active ingredients - or mechanisms - that can be for example stimuli or a condition fostering idea generation such as anonymity. According to Smith [15] there are three types of active ingredients in idea generation methods. The first ingredients are strategies that are mostly mental active means of generating ideas [15]. The second ingredients are strategy-supporting tactics - mostly different kinds of stimuli - and finally enablers that passively support idea generation by fostering beneficial conditions [15]. Herring et al. [17] present a categorization and creative model to categorize idea generation tools used by creative professionals. The categorization of methods comprises three fluid phases of 'research', 'represent', and 'refine' that are all accompanied by inspiration [17]. 
Idea generation methods have also been classified purely into cognition-based categories. Shah et al. [5] classify methods into logical and intuitive methods, and similar classifications have been done by others as well [e.g. 19]. Intuitive methods facilitate idea generation by stimulating unconscious thought processes. Logical methods are more systematic ways of solving and understanding the problem at hand. [5] As their aim was to move to a more detailed, component breakout rather than cognition, Shah et al. [5] also present a set of idea generation 'components' that are present in idea generation methods. These components are divided into two categories based on their ideas of functioning; 'idea generation promoters' e.g. use of analogies and 'tackles' that help overcome a mental block e.g. suspending judgment, which helps to mitigate the effect of too early criticism [5]. In this categorization, mechanisms such as group size or cycle time are ruled out of the categorization as method related operating variables. These, along with design problem variables, human factors, and environment variables [5] are ruled out of the categorization. In this previous classification, therefore, one idea generation method can contain multiple components or elements of multiple approaches. In this work, we update and build on these past classification schemes, without taking a stand on the fundamentality or importance of individual mechanisms.

\subsection{Idea generation methods and mechanisms in literature}

Studies that focus on idea generation methods can be roughly divided into two tracks. In the first track studies compare methods against each other while the second track focuses on adding understanding on what effect a certain idea generation method has on design as an activity or its outcomes [e.g. 4, 20, 21]. 
However, previous research has not only compared methods and tried to understand the effectiveness of methods, but it has also looked deeper into mechanisms that differentiate methods from another. This kind of research includes, for example, priming designers with empathic experiences in order to help them empathize with users while generating ideas [7], finding analogies with a new design [4], the effect of time and incubation to problem solving $[16,22]$ or the use of design heuristics as cognitive strategies that allow a designer to explore existing possibilities [21, 23 ]. Often the interest of researchers is how mechanisms such as stimuli, cognitive priming, evaluating ideas or modality affect idea generation [e.g., 20, 24, 25, 9] or what is fixation [26], what causes it and how to mitigate its effects $[27,28]$.

For example, we know that modality of generating ideas is a mechanism that can have a great effect on the ideas that result from an idea generating session and it has been studied in many ways. Variations and modifications of Osborn's [29] Brainstorming have been compared against each other to understand the effect of modality. It has been found out that written techniques (brainwriting techniques) can overcome many challenges that classical or other verbal versions of Brainstorming have. Written techniques ensure equality of the participants, and push them to participate, eliminate the effect that interpersonal dynamics can have on a session, and can produce more and better quality ideas than classical Brainstorming [30]. Visual techniques have also been studied and compared to written techniques. When comparing Collaborative Sketching (C-Sketch) [e.g. 31] with Method 6-3-5 [32] the sketching method has been found to be more effective when measuring quality, novelty, and variety of designs [31]. While 
sketching can stimulate creativity in a team [33] and produce more and higher quality ideas that written methods, there are also indications that by combining these two modalities the results would be even better when measuring quantity of ideas [9].

The current study builds on this existing knowledge and work on idea generation methods and mechanisms by systematically decomposing well-documented idea generation methods in order to find out the full set of mechanisms present in current ideation methods. We aim at shifting the focus from studying individual methods to studying mechanisms, as some studies visited in this section have already successfully done. Understanding the mechanisms in their entirety is a step towards more fundamental understanding of ways to enhance creativity in the design process.

\section{METHODOLOGY}

This study adopts a qualitative approach, where documented idea generation methods' instructions are used as the stand-alone data.

\subsection{Data gathering}

The data used in this study was gathered by reviewing previous research, books, and Internet sources on idea generation methods and creativity improvement guides. The search was done by an industrial designer and a mechanical engineer but with no particular focus on any one discipline. The search was not limited to scientific sources, as idea generation methods are practical tools and there is an abundance of methods presented by and for design practitioners online and in various design books. First the idea generation methods themselves were searched, followed by collecting the instructions for each method. The instructions were important as data produced for 
practical purposes [34] of idea generation for the analysis. Some of the used instructions were primary documents, i.e. the original descriptions of a method, while some of the method instructions used were secondary documents, meaning that the method was described by someone other than the originator. We do not see this as a limitation, as this is in the nature of practitioner-oriented idea generation methods. However, the original descriptions and instructions of methods were used when possible. For some methods multiple documented instructions were consulted to create a better understanding of the procedure. The concept of inductive thematic saturation was applied in this study, i.e. new data was gathered until no new idea generation mechanisms were found in the method instructions as new methods were found (see Figure 1). Saturation was first checked after the initial 76 methods of the found 114 methods were analyzed. To ensure saturation, additional 13 methods were added to the data out of which 12 satisfied the inclusion criteria and were added to the analysis (10\% addition to the original 114 methods). No new mechanisms were found.

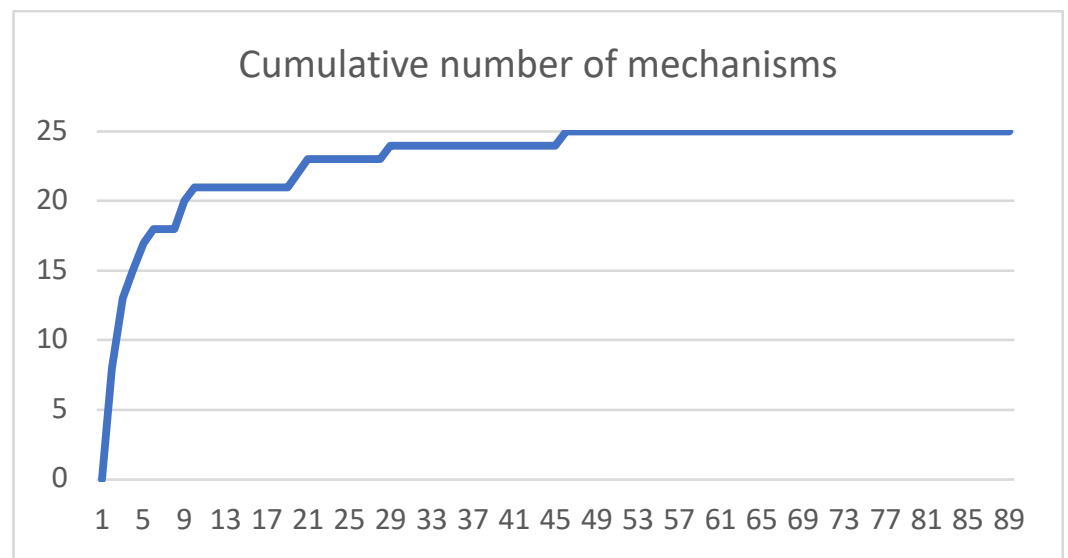

Fig. 1 Cumulative number of mechanisms found 
The analyzed method instructions included different levels of the idea generation methods. That is, at one extreme were processes that take the participant(s) from problem formation to choosing the idea or ideas to be further developed, whereas at the other extreme were methods that are implemented into other methods or used alone in order to spark ideas. Despite this difference in the level of intensity all of the methods included in the analysis had the same aim - to help people generate ideas. Despite the differences in the level of comprehensiveness all methods were analyzed in the same manner, focusing on the instructions and descriptions of the methods. In our definition of what constitutes as a method in this study we therefore follow Smith [15] (p.109) when he writes, "A technique is a prescription. They range from highly structured procedures to informal pieces of advice."

\subsection{Inclusion and exclusion criteria}

The collected data ultimately included 127 methods and their instructions. This study focused only on methods that were created for idea generation phase of a design process. There are plenty of methods that are created for previous or subsequent phases of a design process. These are useful for helping in understanding the problem at hand, selecting ideas, taking the ideas further, and developing them into feasible concepts. However, those methods are outside the scope of this study. Therefore, some of the collected methods were ruled out from the analysis. For example, Factorization that was suggested as a systematic problem solving method by Pahl \& Beitz [19] was left out, as it is a method for defining and breaking down the problem before idea generation rather that a method for generating solution alternatives. Idea generation 
methods that were not actionable i.e. had no clear instructions were ruled out as well. For example, Prototyping [17] is certainly useful in idea generation, but this method had no clear instructions, thus it was ruled outside the scope of this study as a nonactionable method. If a method's only instruction was a suggestion such as to let one's mind wonder or to think laterally and understand the big picture, they were also ruled out of the analysis as non-actionable. Even if the method's essence might have sounded vague or general (e.g. to take a break from idea generation), it was included in the analysis if there was an actionable instruction for how to put it into action.

After checking each method against the inclusion criteria, $\mathbf{8 8}$ idea generation methods were included in the analysis (See Appendix A for a list). Some of these 88 methods were modifications of other methods, but the modification was included if its instructions were different from the previous method. In cases where the execution of a session would be identical to other modifications of the same technique, only one method was chosen for analysis. Methods that were identified as the same method under different names were treated as one in the analysis. For example, SCAMPER [35] and its extension SCAMMPERR [36] were taken into account only once under the name of SCAMPER as the extension is only adding two stimulating action verbs and not changing the execution of the method.

\subsection{Data coding and analysis}

The final set of method instructions was divided into steps method by method. The coding consisted of searching these steps for descriptions of how to put the method in use and highlighting each independent segment. These segments were then coded 
into categories based on the described mechanism (Table 1). The coding categories of

mechanisms were developed iteratively during the data gathering and analysis.

Table 1 Examples of segmenting and coding mechanisms from method

instructions. The found mechanisms are bolded in the examples.

\begin{tabular}{|c|c|c|}
\hline & Segmented method instruction & Coded mechanisms \\
\hline 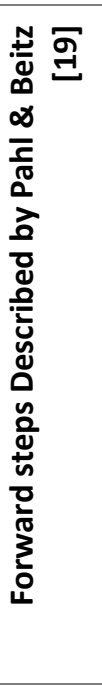 & $\begin{array}{l}\text { "Starting from a first solution attempt, one follows as } \\
\text { many paths as possible to produce further solutions. This } \\
\text { method is also called the method of divergent thought. It is } \\
\text { not necessarily systematic, but frequently starts with an } \\
\text { unsystematic divergence of ideas. The method is illustrated } \\
\text { in Figure } 2.21 \text { for the development of a shaft-hub } \\
\text { connection (coder's note; drawings and writing describing } \\
\text { solution possibilities). The arrows indicate the direction of } \\
\text { the thinking process. } \\
\text { Such a thinking process can be improved by using } \\
\text { classifying criteria (coder's note; a figure including } \\
\text { stimulation words) to support the systematic variation of } \\
\text { the characteristics (coder's note; an example figure). } \\
\text { Where variation is done without conscious thought, even } \\
\text { with well-structured representations, the identified } \\
\text { characteristics are not used to their full potential." }\end{array}$ & $\begin{array}{l}\text { Modality: drawings, Modality; } \\
\text { written } \\
\text { Modality: thought process, } \\
\text { Classification of ideas, } \\
\text { Stimulation, Combination\& } \\
\text { modifications, }\end{array}$ \\
\hline 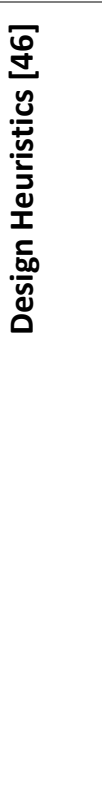 & $\begin{array}{l}\text { We developed a set of Design Heuristics that are intended } \\
\text { to facilitate idea generation. Instead of aiming to generate a } \\
\text { single solution, the goal is to promote the generation of } \\
\text { multiple, diverse ideas through repeated application of } \\
\text { different Design Heuristics. For the current study, each } \\
\text { heuristic is presented in the form of a card, which includes } \\
\text { a title, a descriptive action prompt, an abstract image, and } \\
\text { two product examples. On the front of the card, the action } \\
\text { prompt provides specific instructions on how to modify an } \\
\text { existing idea, or gives features to build a new idea. The } \\
\text { abstract image is intended to supplement the action } \\
\text { prompt by representing it visually. On the back of the card, } \\
\text { the first product example comes from a variety of } \\
\text { consumer products, while the second one offers an } \\
\text { example from a consistent object (seat or chair). This is to } \\
\text { show that the heuristics apply to a wide range of products } \\
\text { and that every heuristic can be applied to the same product } \\
\text { category. // Students were asked to draw their concepts on } \\
\text { separate papers. }\end{array}$ & $\begin{array}{l}\text { Team/ Individual; } \\
\text { Open-ended duration (detailed } \\
\text { elsewhere in the source) } \\
\text { Aiming at high amount of ideas, } \\
\text { Special tool (cards) } \\
\text { Stimulation } \\
\text { Combination \& Modifications, }\end{array}$ \\
\hline
\end{tabular}


The categories rose both from literature and the data. The analysis started with literature-based categories. For example, the first phases of coding included a category of a "specific problem", which illustrated the starting point of the session and whether the problem was explicated as it appeared in some of the method descriptions. It was later removed as the authors came to the conclusion that having a specific problem to ideate around is an implicit assumption in all situations where idea generation methods are used. Some categories were also merged. In the first phase of coding there were separate categories for inspiration and priming. Later these two and all other stimuli were categorized in one category of stimulation, as both using inspirational material [37] and priming essentially are about presenting cognitive stimulus to activate and affect one's thinking [38]. Finally, a clear definition was created for each category, and the definitions were used in coding all the methods.

Ultimately we identified 25 final mechanisms that we used as coding categories (Tables 2 and 3). Based on thematic similarity the coding categories were divided into two top-level types: implementation and idea promoting mechanisms; and these two were divided further into six sub-types. This division will be further discussed in Section 4.

Table 2 Descriptions of identified implementation mechanism categories

\begin{tabular}{ll}
\hline Implementation mechanisms \\
\hline Mechanism & Definition of the mechanism \\
\hline Team & $\begin{array}{l}\text { Methods that can be used or are designed to be used in a team. Even if the } \\
\text { method is for team use it might contain phases where participants work } \\
\text { individually. These kinds of methods were tagged only as team methods, as } \\
\text { they are unfunctional without the team element. }\end{array}$ \\
\hline
\end{tabular}




\begin{tabular}{|c|c|c|}
\hline & Individual & $\begin{array}{l}\text { Methods that can be used or are designed to be used individually. If a method } \\
\text { can be applied both for a team or an individual it contains both mechanisms. }\end{array}$ \\
\hline \multirow{3}{*}{ 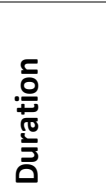 } & Given & Duration for using the method is given. \\
\hline & Decide & Duration for using the method is up to the users to decide. \\
\hline & $\begin{array}{l}\text { Open- } \\
\text { ended }\end{array}$ & $\begin{array}{l}\text { Duration for using the method is open, the session ends when no new ideas } \\
\text { emerge or the instructions have no mention of duration. }\end{array}$ \\
\hline \multirow{5}{*}{$\begin{array}{l}\frac{i}{\frac{2}{\pi}} \\
\frac{\pi}{2} \\
\sum\end{array}$} & Written & $\begin{array}{l}\text { Ideas are written down as they emerge. For example, an advice to "make a } \\
\text { list" would be an example of written modality. }\end{array}$ \\
\hline & Verbal & $\begin{array}{l}\text { The ideas are expressed in a spoken, verbal form. If ideas are first only spoken } \\
\text { out loud and then collated into a list in the end of the session as a way of } \\
\text { collecting them for further use, the only acknowledged mode is verbal. }\end{array}$ \\
\hline & Physical & Ideas are generated and expressed by acting physically. \\
\hline & Visual & $\begin{array}{l}\text { Ideas are expressed as sketches and drawings. Mock-ups or low fidelity } \\
\text { prototypes also count as visualizations of ideas. }\end{array}$ \\
\hline & Thought & Idea generation is done as a chain of thought. \\
\hline \multirow{2}{*}{ 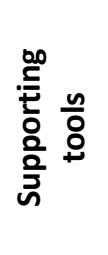 } & $\begin{array}{l}\text { Facilitatio } \\
\text { n }\end{array}$ & $\begin{array}{l}\text { A facilitator leads an idea generation session. The facilitator might just keep } \\
\text { track of the activities or lead the session without taking part in generating } \\
\text { ideas. }\end{array}$ \\
\hline & $\begin{array}{l}\text { Special } \\
\text { tool use }\end{array}$ & $\begin{array}{l}\text { Using a tool such as a ready-made form, matrix, game or software as a part of } \\
\text { the idea generation session. Tools such as sticky-notes or paper were not } \\
\text { coded as special tools. }\end{array}$ \\
\hline
\end{tabular}

Table 3 Descriptions of identified idea promoting mechanism categories

\begin{tabular}{|c|c|c|}
\hline \multicolumn{3}{|c|}{ Idea promoting mechanisms } \\
\hline Me & anism & Definition of the mechanism \\
\hline \multirow{5}{*}{ 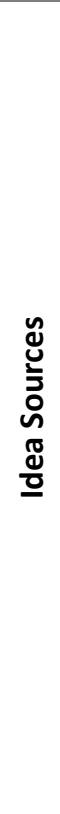 } & Analogies & $\begin{array}{l}\text { Utilizing analogies in idea generation session. Participant(s) are guided to } \\
\text { intentionally draw analogies from one domain to another. The sources of } \\
\text { analogies can include e.g. other industries, nature or products. Analogous } \\
\text { designs share at least one function or behavior [e.g. 39]. }\end{array}$ \\
\hline & Association & $\begin{array}{l}\text { Using associations, i.e. generating ideas with the help of associations from e.g. } \\
\text { words, previous ideas, pictures, situations or nature, the outcomes are } \\
\text { unintentional to an extent. The seen word, picture etc. is used as a prompt for } \\
\text { the next idea even if there is no logical connection. }\end{array}$ \\
\hline & $\begin{array}{l}\text { Building on } \\
\text { others }\end{array}$ & $\begin{array}{l}\text { Participants are encouraged to build on others' ideas while the ideas are created } \\
\text { or stated. Also rotating ideas or thoughts to other participants and building on } \\
\text { those ideas. }\end{array}$ \\
\hline & Incubation & $\begin{array}{l}\text { Incubation period or phase as a part of the method. It is a period of time when } \\
\text { problem is set aside before going back to solving it [e.g. 16]. }\end{array}$ \\
\hline & Stimulation & $\begin{array}{l}\text { Using stimuli to prompt ideas. For example, using stimulating pictures, questions } \\
\text { or words or adapting a role to tease out ideas. Method might include collecting } \\
\text { and using inspirational material or influencing the subconscious either by } \\
\text { exposing the participant(s) to pictures, sounds, words or other ways to influence } \\
\text { idea generation and activate thinking to help in accessing already existing } \\
\text { knowledge. }\end{array}$ \\
\hline \multirow{2}{*}{ 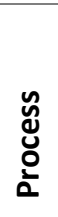 } & $\begin{array}{l}\text { Aiming at a } \\
\text { high amount } \\
\text { of ideas }\end{array}$ & $\begin{array}{l}\text { An emphasis on quantity, and an aim to create a mass of ideas as opposed to } \\
\text { creating only few ideas. This is often implicit in method instructions, or this } \\
\text { might be the result of repetition of certain steps as e.g. in Method 6-3-5. }\end{array}$ \\
\hline & Classification & $\begin{array}{l}\text { A phase in an idea generation method where ideas are classified or grouped as } \\
\text { a part of using the method. }\end{array}$ \\
\hline
\end{tabular}




\begin{tabular}{ll}
\hline $\begin{array}{l}\text { Combination } \\
\text { Modifications }\end{array}$ & $\begin{array}{l}\text { Combining, synthesizing or modifying ideas as a part of the idea generation } \\
\text { session in order to create new ideas and meanings. Modified ideas can be either } \\
\text { ideas created during the session or existing products, things, ideas or meanings. }\end{array}$ \\
\hline Evaluation & $\begin{array}{l}\text { A phase in an idea generation method where ideas are evaluates as a part of } \\
\text { using the method. }\end{array}$ \\
\hline Framing & $\begin{array}{l}\text { Framing here includes rephrasing or re-framing the problem. Cutting the } \\
\text { problem into smaller entities or maybe reversing it. Sometimes there is a focus } \\
\text { on setting the problem into a context or defining the problem before starting to } \\
\text { generate ideas to solve it. This is done in order to eliminate constraints and } \\
\text { widen or limit the scope of search. }\end{array}$ \\
\hline Iterations & $\begin{array}{l}\text { Iterative process in idea generation methods, where ideas are generated } \\
\text { cyclically. }\end{array}$ \\
\hline Selection & $\begin{array}{l}\text { A phase in an idea generation method where one or more ideas are selected for } \\
\text { some further use, to be e.g. generated further, built upon, to be presented or to } \\
\text { be shared. }\end{array}$ \\
\hline $\begin{array}{l}\text { Suspend } \\
\text { judgment }\end{array}$ & $\begin{array}{l}\text { Suspending premature judgment and evaluation of ideas during idea generation } \\
\text { in order to produce a variety of ideas. Sometimes method instructions do not } \\
\text { specifically state to suspend judgment, but to be open to e.g. "crazy ideas" or } \\
\text { "all ideas". }\end{array}$ \\
\hline
\end{tabular}

According to the instruction segmentation, each method was coded as either

belonging (1) or not belonging (0) to the developed coding categories. This decision was made by judging whether the mechanisms the categories represented were found in the segmented method instruction or not (Table 1).

If the segment included examples of or references to e.g. drawings it was assumed that the participants were being advised to draw even if drawings were not explicitly mentioned. Some instructions included also scales from one to five describing whether the method was useful for an individual or a team. In a case of the participants not being mentioned in the instructions this kind of indicators were taken into account as a part of the coding. Otherwise only mechanisms mentioned explicitly in the segments were coded into the relevant categories using category descriptions (Tables 2 and 3) as a coding guideline. The categories are not mutually exclusive. For example, a 
method could be both team and individual method or utilize both stimulation and analogies.

\subsection{Inter-rater reliability analysis}

To ensure the reliability of the primary coders coding decisions, a second coder coded $15 \%$ of the data. The second coder worked independently starting from a randomly selected set of method instructions. The segmented steps and mechanisms found by the initial coder were not available for the second coder but he searched for those himself. The second coder then proceeded to decompose the methods into categories. The initial Cohen's Kappa for the all the categories together was 0.82, ranging from 0.42 to 1 . However, in seven categories the coders disagreed in multiple cases and the initial Cohen's Kappa in those categories varied from 0.42 to 0.62 . These categories were re-coded with an improved coding instruction. After re-coding Cohen's Kappa for the all the categories together was 0.93 , ranging from 0.74 to 1 . Cohen's Kappa over 0.7 is regarded sufficient [40]. Once this Cohen's Kappa was achieved a single coder continued to code the rest of the data.

\section{RESULTS}

This section discusses the results of analyzing the instructions of 88 idea generation methods. The results are divided into two sections based on the idea generation mechanism types identified as a part of the analysis. We found there are two types of mechanisms (Tables 2 and 3): implementation mechanisms and idea promoting mechanisms. Implementation mechanisms define the practicalities of an idea generation session; therefore, they could be seen as the functional characteristics of the 
methods. They concern for example how long an idea generation session takes, who takes part in it and how the ideas are expressed. They are not idea triggers as such but more technical level details of utilizing a method. Idea promoting mechanisms, on the other hand, advance the generation of ideas by triggering cognition through either the sources or process of generating ideas. These two types of mechanisms could be further divided into subtypes based on their characteristics. The methods analyzed as a part of this study consisted of three to thirteen mechanisms with an average of 6,8 mechanisms per method.

\subsection{Implementation mechanisms}

The implementation mechanisms we found could be divided into four sub-types. These include mechanisms defining participants, modality, duration, and use of supporting tools. We will describe the categories belonging to the sub-types as well as their occurrence in the analyzed 88 method instructions.

\section{$\underline{\text { Participants }}$}

The method instructions included instructions to either use the method individually or with a team. A majority of the methods, $50 \%$ (44), were reported as team only methods while $17 \%(15)$ were meant for only individual use. Nineteen of the methods (22\%) could be used by either a team or an individual and $11 \%(10)$ of the method instructions had no indication whether it was for team or individual use. Altogether $72 \%$ (55) of the methods were team methods and 39\% (30) were individual methods.

Modality 
The modality categories described the mode in which the ideas were expressed during idea generation. Most methods utilized writing at least in some phase, with $71 \%$ (54) being written methods. Out of all the methods 38\% (29) were verbal, $20 \%$ (15) were indicated as thought processes, $17 \%$ (13) utilized visualizations, and only $8 \%(6)$ had physical modality. Most methods, $60 \%$ (49) utilized only one modality while $36 \%$ (32) of the methods utilized or could be done in two or more different modes. The modalities occurring together were usually written and verbal modality (23\%, 20 methods) possibly accompanied with other modalities as well. Out of all analyzed methods $30 \%(26)$ were written only, $10 \%$ (9) were thought only, $6 \%$ (5) were verbal only, $6 \%$ (5) were visual only, and 3\% (3) were physical only in regards of modality. The instructions of eight methods (9\%) did not specify or indicate the modality.

\section{Duration}

We found three types of duration in the instructions; open-ended, given or cases where the duration is to be decided by the participant(s). Most of the method instructions, $77 \%$ (68), did not specify the time to be used in a creative session, the duration was open. These sessions could be run as long as ideas emerge, or when the participant(s) feel like ending the session. In $16 \%$ (14) of the methods participant(s) were instructed to decide on the duration of the session and in $14 \%$ (12) of the methods the timeframe for the session or some parts of it was given in the instructions (e.g. Method 6-3-5). In 3\% (3) of the methods duration was both open and for the participant(s) to decide and in $4 \%$ (4) there was a given duration and/or the participants 
could decide. The latter was usually due to different phases of the session having different instructions regarding time.

\section{Supporting tools}

Some of the coded segments described using tools to support ideas generation. We identified two supporting mechanisms; having a facilitator and using a special tool. Facilitation was required, suggested or otherwise indicated to be used in $31 \%$ (27) of the methods. This could be either a participant in the session or a person whose only task was to facilitate the idea generation session. A special tool was used by $15 \%$ (13) of the analyzed methods. The tools varied from databases and ready-made templates to online platforms or programs.

To summarize, most common separately manifested implementation mechanisms were open-ended duration (77\%), team as idea generator (72\%), written modality (61\%) individual as the actor (39\%), and facilitation. The rarest implementation mechanism was by far physical modality with only $7 \%$ of the methods. Given duration (14\%), visualizations as modality (15\%), special tool use (15\%), and duration to be decided (16\%) were also relatively rare mechanisms.

\subsection{Idea promoting mechanisms}

The idea promoting mechanisms we found were divided into two sub-types, idea source- and process-related mechanisms. We will describe the categories belonging to the sub-types as well as their occurrence in the analyzed methods.

\section{$\underline{\text { Idea sources }}$}


This sub-type includes five identified mechanisms; association, analogies, building on others, incubation, and stimulation. These mechanisms work as cognitive triggers to help producing new ideas. The use of different kinds of stimuli to trigger creative thinking and promote idea generation turned out to be very common, as $57 \%$ (50) of all 88 methods had such elements, e.g. going through inspirational material, using stimulating words or roles or priming the participants minds. In $28 \%$ (25) of the methods participants were guided to build on others ideas as a way of generating new solutions. Using analogies was advised in $17 \%$ (15) of the methods, and making associations was utilized in $10 \%$ (9) of the methods. Incubation was utilized in $5 \%(4)$ of the method instructions.

\section{Process}

A group of process defining mechanisms was also identified in the idea promoting mechanisms. These mechanisms seem to help idea generation through adding phases to the process that force or facilitate producing new ideas. The following mechanisms were identified: aiming at a high amount of ideas, combining and modifying, suspending judgement, classification, evaluation, iterations, framing, and selection. Taking advantage of combining and modifying existing products and concepts or ideas generated in the session was present in $36 \%$ (32) of the methods. In $24 \%$ (21) of the methods the session included a phase of framing the given problem. Aiming at a high amount of ideas was described in $23 \%$ (20) of the instructions, and advising towards suspending from judgement during idea generation was present in $20 \%$ (18) of the methods. Phases of evaluating as well as iterating were present in an equal amount 
of methods appearing in $18 \%$ (16) of the analyzed instructions. Classifying or selecting ideas as a part of the session was rather rare in the methods, with classifying showing up in $13 \%(11)$ and selecting in $10 \%$ (9) of the analyzed methods.

It can be seen that the majority of the identified idea promoting mechanisms manifested in the methods quite evenly, while few mechanisms stood out as more common or rarer than others. However, three mechanisms stood out as the most common and four as less used idea promoting mechanisms. The most common idea promoting mechanisms were using stimuli (57\%), combination and modifications (36\%), and building on others ideas (28\%). The most seldom occurring idea promoting mechanisms were classification (13\%), association (10\%). selection (10\%), and incubation (5\%).

\section{DISCUSSION AND IMPLICATIONS}

In the presented study 88 idea generation methods were collected and analyzed from the perspective of the method comprising elements we call mechanisms. This section discusses the findings and their relevance, as well as a framework for of idea generation mechanisms based on the findings.

The results suggest that idea generation methods consist of two types of mechanisms. These mechanisms either dictate the implementation of the method, how an idea generation session should be set up, or act as promoters for idea generation by bringing process- or cognition-related elements to an idea generation session. Most studies on idea generation methods focus on understanding the effectiveness of certain method or the effect of a certain mechanism. The main contribution of this study is an updated 


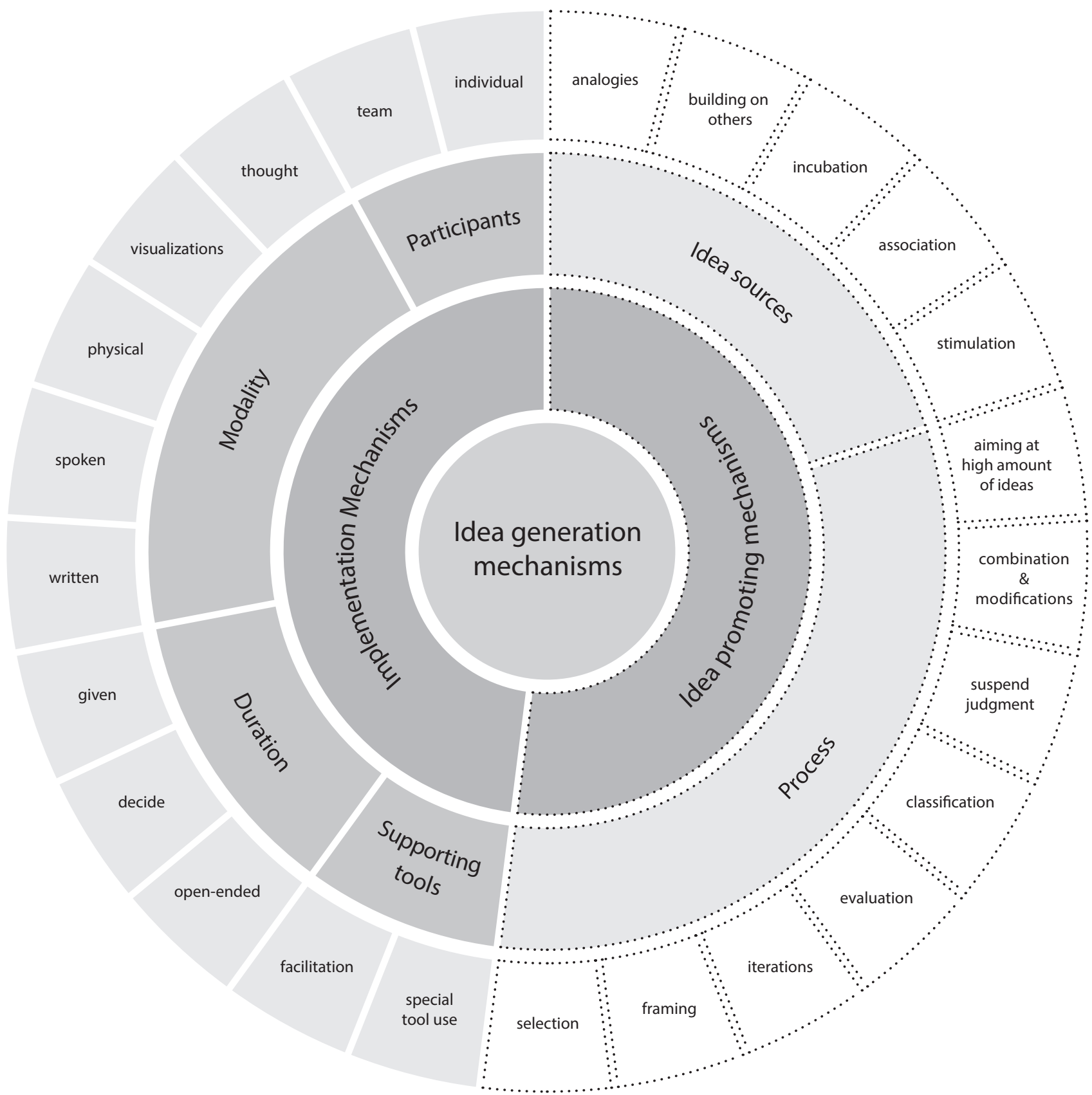

Fig. 2 The resulting framework of creativity mechanisms in idea generation methods

understanding of the entity of idea generation mechanisms. We also present suggestive findings of their frequency in methods. These mechanisms constitute the backbone of all idea generation methods (Figure 2). 
It should be noticed, that as a part of this study no attempts of forming a hierarchy of these identified mechanisms were made. This is something that could be pursued, and a difference in the level of intensity between the mechanisms could be identified even in the recent results. This is in in line with the work of Vargas-Hernandez et al. [6]. Some of the discovered mechanisms are cognitive while some are practical however, this is a reflection of how the method instructions are in where these mechanisms were drawn from. The current study does not address this difference. Thus, the aim, potential use, and value of the framework is in making an attempt of providing a holistic view of the multitude of mechanisms that are at play when applying the mechanisms in practice - which often means using a pre-existing idea generation method.

We also found that as idea generation methods seem to consist of mechanisms that occur often in seemingly very different methods, it was not possible to group the analyzed methods themselves into categories defined by these mechanisms. A cluster analysis was attempted, but the results showed no clear method types, groups, or patterns.

For example, when comparing e.g. Bodystorming [41] and Mind-mapping [42] against one another, they appear quite different at first. One immerses participants physically into the situation or problem at hand and stimulates thinking through action, while the other stimulates thinking through systematically solving a problem branch by branch in writing. The instructions differ in implementation mechanisms (modality, duration, and participants), but they share an important idea promoting mechanism - 
stimulation. This similarity can be seen when decomposing the methods into mechanisms. If we were to reduce the implementation mechanisms the two methods appear alike. Therefore, we suggest that research on idea generation should look beyond methods, as the entity is more complex. When studying methods instead of mechanisms the results are not as comparable as they would be if focused on mechanisms. Effectively, comparing a method to another is actually comparing a specific group of mechanisms and their interactions. While that is also a valuable goal, a more basic understanding of the mechanisms alone and their simpler interactions should be gained first.

As said, the identified mechanisms differ from each other and they affect idea generation on various levels. Therefore, we suggest that comparative studies should be planned in a way that the comparisons are relevant. Comparing mechanisms across the two identified types or sometimes even subtypes of mechanisms is not necessarily something that should be pursued. However, comparisons between mechanisms that can be used as alternatives to each other can produce interesting knowledge on these mechanisms $[43,44]$. This has also been the case in previous studies, where e.g. modality has been studied $[9,33]$. For example, as sketching has proven to be more efficient than writing alone [31], Method 6-3-5 has also evolved into using visual techniques, instead of only writing down ideas. There are multiple possibilities for testing different mechanisms in action. For example, what is the effect of adding classification to SCAMPER or changing the modality of e.g. Rolestorming [45] into visual. 
There were some mechanisms that were found in only a few method instructions and some that dominated the methods. For example, incubation appeared only in four methods, which was a surprising discovery, as incubation is a wellresearched mechanism that has a positive effect on idea generation by widening the search for solution to new areas [16, 22]. When a problem is re-approached after an incubation period the search is extended [16]. Given the benefits, incubation seems to be an under-exploited mechanism in the existing idea generation methods based on the results of the current study. Also classifying or selecting ideas during the idea generation session were little used. They are also mechanisms whose effects on idea generation have not been widely studied yet both have been shown to have a positive effect on idea novelty [43]. One dominating mechanism was written modality (61\%) when compared to visual modality (15\%) as most methods include writing down ideas. This is in conflict with what we know of the benefits of visual [33] or combined visual and written modality [9]. Also using open-ended duration dominated the methods (77\%), this outcome is backed up by previous findings that show how longer periods of time used for idea generation positively affect the diversity of the solutions created [22].

The value of recognizing the dominating or underused mechanisms opens possibilities of adapting methods, mixing mechanisms or even creating whole new methods. The reason some well researched mechanisms recognized as dominant in creativity and learning were not more recurring in the data could be that in reality these useful ways of advancing creativity are not present in the method instructions. Instead they might be mechanisms that humans intuitively gravitate towards without being 
instructed to do so. It is also interesting to notice how the scientific knowledge on improving creativity in idea generation is not always reaching the practitioners. Some effective mechanisms were rarely present the analyzed methods. This we identify as a place for improvement for the science community.

Modifying methods based on mechanism knowledge and current needs could create a better starting point than possibly choosing a method or even modifying it based on intuition, which is what often happens in practice. Thus, one of the applications of the results presented here is to use the framework as a tool to become aware of ones' choices and possibilities, so that idea generation can be modified to reach a larger variety of ideas. Recognizing the mechanisms in methods also helps in searching for different methods to be taught to future designers or to be used in a project by practitioners. Design students are usually taught and professionals know a suite of creativity methods. By becoming aware of the mechanisms that make each method, and which methods are dominating or rare, we can make more conscious choices and select methods that consist of different mechanisms. This could help students in understanding the multi-faceted nature of idea generation and the relevance of methods for creativity. We see that making conscious choices to widen the used variety of creativity promoting mechanisms can also help practitioners striving to create innovative ideas. A recent study showed, that cognitive support - Design Heuristics in this case - could help in pushing past the exhaustion point of creativity and generating additional, even more novel ideas [23]. We suggest that the framework resulting from our study could be used as tool for finding actionable supporting 
mechanisms to try in similar situations. A slightly provocative practical implication could be an instruction to forget about methods when generating ideas and instead trying out mechanisms and then choosing suitable ones to exploit.

This work opens several avenues of future work. Each of the mechanisms and their combinations could be studied to understand how they affect creativity. The mechanisms might perform differently for different types of problems, and different types of teams might benefit from different mechanisms or mechanism combinations. Some early work has found classification and combination mechanisms to perform approximately equally for both simple [43] and more complex [44] problems, but more work is needed to fully understand the mechanisms.

Some limitations can be identified in the current study. First, the documented method instructions used as data are only one interpretation or description of each method. The results might be slightly different if synthesizing multiple instructions into one for the analysis. However, in some cases this was done, as described in Section 3. What might also bias the occurrence of mechanisms results is that all instructions do not specify all mechanisms, e.g. modality, if there are iterations or if the method should be used by individuals or team. In those cases, the mechanisms that were not coded might cause a bias. Therefore, the results regarding the frequency of mechanisms cannot be generalized.

There are also idea generation methods that could not be included in this study because no instructions were available. Many methods are used in practice as modifications of methods. There are multiple variations of Brainstorming for example. 
These variations were not taken into account. There are also methods not included in this study. However, as the aim of this study was identifying mechanisms rather than identifying methods, this should not affect the results after reaching saturation as described in Section 3.

\section{CONCLUSIONS}

A framework of 25 creativity mechanisms grouped into idea promoting and implementation mechanisms was generated. These groups can be further divided into sub-types. The division generated as a part of this study consists of two sub-types for idea promoting mechanisms: idea sources and process related mechanisms. Idea sources include mechanisms that are actively used to prompt ideas. These mechanisms are analogies, association, building on others, incubation, and stimulation. Process mechanisms are related to how the idea generation process is carried out and the concrete steps of action. The sub-group consists of the following mechanisms: aiming at high amount of ideas, classification, combination \& modifications, evaluation, iterations, framing, selection, and suspending judgment. The implementation mechanisms are divided into four sub-types that are duration, modality, participants and supporting tools.

When moving to a more detailed level, more mechanisms could be formed. For example, stimulation as a mechanism can be further divided into different forms of stimulation according to what kind of stimuli is used or how the stimulus is used. Likewise, visual modality could be further divided into different ways of visualizing, for example building prototypes to think by doing and sketching. We also considered a 
possibility to combine some of the identified mechanisms, as there is some overlap between them. For example, we acknowledge that using analogies and association are closely related actions. However, in this framework they are kept apart, as they were separately mentioned in the data and they have different definitions.

We suggest approaching idea generation mechanisms as building blocks or a "cook book" that allows trial, play, and being creative about creativity methods. Looking at idea generation mechanisms as almost interchangeable blocks opens up a nearly endless possibility for generating new methods or modifying idea generation methods by switching or adding mechanisms into existing methods.

\section{REFERENCES}

[1] Cross, N., 2000, “Engineering Design Methods: Strategies for Product Design," pp: 46-59. John Wiley \& Sons, Chichester.

[2] Sarkar, P., and Chakrabarti, A.,2017, "A Model for the Process of Idea Generation," The Design Journal, 20(2), pp. 239-257.

[3] Runco, M. A., and Jaeger, G.J.,2012, "The standard definition of creativity," Creativity research journal, 24(1), pp 92-69.

[4] Linsey, J.S., Wood, K.L., and Markman, A.B.,2008, "Increasing innovation: presentation and evaluation of the wordtree design-by-analogy method," Proceedings of the ASME IDETC/CIE. DETC2008-49317: pp. 21-32. Brooklyn, New York, August 3-6,

[5] Shah, J.J., Kulkarni, S.V., and Vargas-Hernandez, N., 2000, "Evaluation of idea generation methods for conceptual design: effectiveness metrics and design of experiments," Journal of mechanical design, 122(4), pp. 377-384.

[6] Vargas-Hernandez, N., Shah, J.J., and Smith, S.M., 2010, "Understanding design ideation mechanisms through multilevel aligned empirical studies," Design Studies, 31(4),pp. 382-410

[7] Genco, N., Johnson, D, Hölttä-Otto, K., and Seepersad, C.C., 2011, "A study of the effectiveness of empathic experience design as a creativity technique," Proceedings of the ASME IDETC/CIE. DETC2011-021711: pp 131-139, Washington, DC, August 28-31. 
[8] Hey, J., Linsey, J.S., Agogino, A.M., and Wood, K.L., 2008, "Analogies and metaphors in creative design," International Journal of Engineering Education, 24(2), pp. 283-294.

[9] Linsey, J.S., Green, M.G., Murphy, J.T., Wood, K.L., and Markman, A.B., 2005, "Collaborating To Success: An Experimental Study of Group Idea Generation Techniques," Proceedings of the ASME IDETC/CIE. DETC2005-85351: pp. 277-290. Long Beach, California, September 24-28.

[10] Takahashi, M., 2007, "The Japanese Creativity Education and Creativity Techniques: A Perspective from the Enterprise," In A.G. Tan (Ed.) Creativity: A Handbook for Teachers (pp. 327-339). World scientific, Singapore.

[11] Kumar, V., 2012, "101 design methods: A structured approach for driving innovation in your organization," John Wiley \& Sons, Hoboken.

[12] Martin, B., and Hanington, B., 2012, "Universal Methods of Design: 100 Ways to Research Complex Problems, Develop Innovative Ideas, and Design Effective Solutions," Rockport Publishers, Beverly.

[13] Higgins, J., 1994, M. "101 Creative Problem Solving Techniques: The Handbook of New Ideas for Business," New Management Publishing Company, New York.

[14] De Bono, E., 1995, “De Bono's thinking course, “ BBC, London.

[15] Smith, G. F., 1998, "Idea-generation techniques: a formulary of active ingredients." The Journal of Creative Behavior, 32(2), pp. 107-134.

[16] Sio, U.N., Ormerod, T.C., 2009, "Does incubation enhance problem solving? A meta-analytic review," Psychological Bulletin, 135(1), pp. 94-120.

[17] Herring, S.R., Jones, B.R., and Bailey, B.P., 2009, "Idea generation techniques among creative professionals," 42nd Hawaii International Conference on System Sciences.

[18] Fulmer, R.M., 1988, "The new management," Macmillan College, New York.

[19] Pahl, G., and Beitz, W., 2007, “Engineering design: a systematic approach," 3. ed. Springer Science + Business Media. London.

[20] Lopez-Mesa, B., Mulet, E., Vidal, R., and Thompson, G., 2011, "Effects of additional stimuli on idea-finding in design teams," Journal of Engineering Design, 22(1), pp. 31-54. 
[21] Yilmaz, S., Daly, S.R., Seifert, C.M., and Gonzalez,R., 2015, "How do designers generate new ideas? Design heuristics across two disciplines." Design Science, 1(4). doi:10.1017/djs.2015.4

[22] Tsenn, J., Atilola, O., McAdams, D. A. and Linsey, J. S., 2014, "The effects of time and incubation on design concept generation," Design Studies, 35(5), pp. 500-526.

[23] Gray, C.M., McKilligan, S., Daly, S.R., Seifert, C.M., and Gonzalez, R., 2019, “Using creative exhaustion to foster idea generation." International Journal of Technology and Design Education, 29(1), pp. 177-195.

[24] Dennis, A.R., Minas, R.K. and Bhagwatwar, A.P., 2013, "Sparking creativity: improving electronic brainstorming with individual cognitive priming," Journal of Management Information Systems, 29(4), pp.195-216

[25] Hao, N., Ku, Y., Liu, M., Hu, Y., Bodner, M., Grabner, R.H, and Fink, A., 2016, "Reflection enhances creativity: Beneficial effects of idea evaluation on idea generation," Brain \& Cognition, 103, pp. 30-37.

[26] Jansson, D.G., and Smith, S.M., 1991, “Design fixation," Design studies, 12(1), pp. 311.

[27] Atilola, O., Tomko, M., and Linsey, J.S., 2016, "The effects of representation on idea generation and design fixation: A study comparing sketches and function trees," Design Studies. 42, pp. 110-136.

[28] Crilly, N., 2015, "Fixation and creativity in concept development: The attitudes and practices of expert designers," Design Studies, 38, pp. 54-91.

[29] Osborn, A.F., 1957, “Applied Imagination,” Scribner, New York.

[30] VanGundy, A.B., 1984, "Brain writing for new product ideas: an alternative to brainstorming," Journal of Consumer Marketing, 1(2), pp. 67-74.

[31] Shah, J.J., Vargas-Hernandez, N., Summers, J.D., \& Kulkarni, S., 2001, "Collaborative Sketching (C-Sketch) - An idea generation technique for engineering design," The Journal of Creative Behavior. 35(3), pp. 168-198.

[32] Rohrbach, B., 1969, "Kreativ nach Regeln-Methode 635, eine neue Technik zum Lösen von Problemen," Absatzwirtschaft, 12(19), pp. 73-75.

[33] Van der Lugt, R., 2005, "How sketching can affect the idea generation process in design group meetings," Design studies, 26(2), pp. 101-122. 
[34] Flick, U., 2009, "An introduction to qualitative research," Sage, London.

[35] Eberle, R.F., 1972, “Developing imagination through scamper. "The Journal of Creative Behavior, 6(3), pp. 199-203.

[36] Mycoted (Ed.). (n.d.). SCAMMPERR. Retrieved February 17, 2020, from http://www.mycoted.com/SCAMMPERR

[37] Gonçalves, M, Cardoso, C., and Badke-Schaub, P., 2014, "What inspires designers? Preferences on inspirational approaches during idea generation." Design studies, 35(1),pp. 29-53.

[38] Bargh, J.A. and Chartrand, T.L., 2000, "The mind in the middle." Handbook of research methods in social and personality psychology, 2, pp. 253-285.

[39] Qian, L., and Gero, J.S., 1996, "Function-behavior-structure paths and their role in analogy-based design" Artificial Intelligence for Engineering, Design, Analysis and Manufacturing, 10(4), pp. 289-312.

[40] Robson, C., 2002, "Real world research: A resource for social scientists and practitioner-researchers," (2nd ed.). Blackwell: Oxford.

[41] Witthoft, S., \& Geehr, C. (n.d.). Bodystorming (Stanford d.school K12 Lab, Ed.). Retrieved February 17, 2020, from https://dschool-

old.stanford.edu/groups/k12/wiki/48c54/Bodystorming.html

[42] CreatingMinds.org. (n.d. b). Mind-mapping. Retrieved February 17, 2020, from http://creatingminds.org/tools/mind-mapping.htm

[43] Kirjavainen, S., and Hölttä-Otto, K., 2019, "To Classify or Combine: The Effects of Idea Generation Mechanisms on the Novelty and Quantity of Ideas," Proceedings of the ASME IDETC/CIE, IDETC2019-97141, Anaheim, CA. August 18-21.

[44] Deo, S., Hölttä-Otto, K., Bhalerao, Y., and Malge, A., 2019, “Engineering Design Concept Generation: The Effect of Concept Combination and Classification." Proceedings of the ASME IDETC/CIE, IDETC2019-97819, Anaheim, CA. August 18-21.

[45] VanGundy, A.B., 2005, "101 activities for teaching creativity and problem solving," Pfeiffer: San Francisco.

[46] Yilmaz, S., Christian, J.L., Daly, S.R., Seifert, C.M., \& Gonzalez, R., 2011, "Collaborative idea generation using design heuristics," In DS 68-10: Proceedings of the 18th International Conference on Engineering Design (ICED 11), Impacting Society 
Journal of Mechanical Design

through Engineering Design, Design Methods and Tools 10(2), Copenhagen, Denmark, 15.-19.08. 2011, pp. 91-101. 
Journal of Mechanical Design

\section{Figure Captions List}

Fig. 1 Cumulative number of mechanisms found

Fig. 2 The resulting framework of creativity mechanisms in idea generation methods 


\section{Table Captions List}

Table 1 Examples of segmenting and coding mechanisms from method instructions. The found mechanisms are bolded in the examples.

Table 2 Descriptions of identified implementation mechanism categories

Table 3 Descriptions of identified idea promoting mechanism categories 


\section{Appendix A}

The 88 methods included in the analysis, named as they appear in their instructions or combining alternative terms from multiple instructions. Sources of and references to the instructions are provided after each method.

1. Brainstorming

Osborn, A.F., 1957, “Applied

Imagination," Scribner, New York. https://www.mindtools.com/brainstm.ht $\mathrm{ml}$

https://dschool.stanford.edu/wpcontent/themes/dschool/methodcards/brainstorm-rules.pdf

2. Reverse Brainstorming https://www.mindtools.com/pages/articl e/newCT_96.htm http://creatingminds.org/tools/tools_ide ation.htm

3. Starbursting

https://www.mindtools.com/pages/articl e/newCT_91.htm

http://www.designorate.com/starburstin g-method/

4. The Charette Procedure

https://www.mindtools.com/pages/artia rt/newCT_90.htm

http://www.designorate.com/brainstor ming-using-charette-procedure/

5. Crawford slip writing method https://www.mindtools.com/pages/artia rt/newCT_95.htm .htm

http://creatingminds.org/tools/crawford

6. Round-robin brainstorming

https://www.betterevaluation.org/evalu ation-options/roundrobin

https://www.mindtools.com/pages/articl e/round-robin-brainstorming.htm

7. Rolestorming

Kumar, V., 2012, "101 design methods: A structured approach for driving innovation in your organization," John Wiley \& Sons, Hoboken.

VanGundy, A. B., 2005, "101 activities for teaching creativity and problem solving."

Pfeiffer: San Francisco.

https://www.mindtools.com/pages/articl e/rolestorming.htm

8. Role-play

http://creatingminds.org/tools/tools_ide ation.htm

Kumar, V., 2012, "101 design methods: $A$ structured approach for driving innovation in your organization," John Wiley \& Sons, Hoboken.

9. Electronic Brainstorming
Michinov, N., 2012, "Is electronic brainstorming or brainwriting the best way to improve creative performance in groups? An overlooked comparison of two ideageneration techniques." Journal of Applied Social Psychology, 42, E222-E243.

Gallupe, R. B., and Cooper, W. H.,1993, "Brainstorming electronically", MIT Sloan Management Review, October 1993.

https://www.mindtools.com/pages/articl e/online-brainstorming.htm

10. Brainwriting

https://www.smashingmagazine.com/20

13/12/using-brainwriting-for-rapid-ideageneration/

https://www.uco.edu/academicaffairs/cqi/files/docs/facilitator_tools/brainb ra.pdf . Accessed 06/2017.

11. 6-3-5

Pahl, G., and Beitz, W., 2007,

"Engineering design: a systematic approach," 3. ed. Springer Science + Business Media. London.

Rohrbach, B., 1969, "Kreativ nach Regeln-Methode 635, eine neue Technik zum Lösen von Problemen,"

Absatzwirtschaft, 12(19), pp. 73-75.

12. Brainwriting Pool

https://www.mycoted.com/Brainwriting \#BrainWriting_Pool

13. Idea card (pin card) method

https://www.mycoted.com/Brainwriting \#ldea_Card_Method

14. Post-Up http://creatingminds.org/tools/post_up. htm

15. Constrained brainwriting https://www.mycoted.com/Brainwriting \#Constrained_BrainWriting

16. Electronic Brainwriting https://www.uco.edu/academicaffairs/cqi/files/docs/facilitator_tools/brainh an.pdf . Accessed 06/2017.

17. The spreadsheet technique https://www.smashingmagazine.com/20 13/12/using-brainwriting-for-rapid-ideageneration/

18. Interactive brainwriting

https://www.smashingmagazine.com/20 13/12/using-brainwriting-for-rapid-ideageneration/ 
19. Brainwriting game https://www.mycoted.com/Brainwriting \#BrainWriting_Game

20. Metaphorical thinking https://www.mindtools.com/pages/main /newMN_CT.htm

21. Reversal https://www.cleverism.com/18-bestidea-generation-techniques/ http://creatingminds.org/tools/tools_ide ation.htm

22. SCAMPER

http://creatingminds.org/tools/tools ide ation.htm https://litemind.com/scamper/ https://www.mindtools.com/pages/main/nn ewM_CT.htm

Eberle, R.F., 1972, "Developing imagination through scamper. "The Journal of Creative Behavior, 6(3), pp. 199-203.

23. Attribute listing

Herring, S.R., Jones, B.R., and Bailey, B.P., 2009, "Idea generation techniques among creative professionals," 42nd Hawaii International Conference on System Sciences. https://www.mindtools.com/pages/main /newMN_CT.htm

24. Morphological analysis http://creatingminds.org/tools/tools_idi deati.htm

https://www.mindtools.com/pages/main /newMN_CT.htm

25. Matrix analysis

https://www.mindtools.com/pages/mai m/newMN_CT.htm

http://www.creativeadvantage.com/mat rix_analysis.html

26. Six thinking hats

http://creatingminds.org/tools/six_hats. htm

De Bono, E., 1995, “De Bono's thinking course, "BBC, London.

27. Po (Provocation)

http://creatingminds.org/tools/provocati on.htm

De Bono, E., 1995, “De Bono's thinking course, " BBC, London.

https://www.mycoted.com/Provocation

28. Talking pictures

$$
\text { https://www.mycoted.com/Talking_Pict }
$$
ures

29. The list of 100

https://litemind.com/tackle-any-issuewith-a-list-of-100/

30. Listing

https://www.mycoted.com/Listing

Whiting, C. S., 1958, "Creative thinking " (Vol. 1). New York.
31. Heuristic ideation technique (HIT)

Tauber, E.M., 1972, “Marketing Notes and Communications: Hit: Heuristic Ideation Technique-A Systematic Procedure for New Product Search." Journal of Marketing, 36(1), pp. 58-61.

https://www.mycoted.com/Heuristic_Id eation_Technique

32. Design Heuristics

Yilmaz, S., Christian, J.L., Daly, S.R., Seifert, C.M., \& Gonzalez, R., 2011, "Collaborative idea generation using design heuristics," In DS 68-10: Proceedings of the 18th International Conference on Engineering Design (ICED 11), Impacting Society through Engineering Design, Design Methods and Tools 10(2), Copenhagen, Denmark, 15.-19.08. 2011, pp. 91-101.

Christian, J. L., Daly, S, R., Yilmaz, S, Seifert, C, and Gonzalez, R, 2012,"Design Heuristics Support Two Modes of Idea Generation: Initiating Ideas and Transitioning Among Concepts" Industrial Design Conference Presentations, Posters and Proceedings. 3.

33. TRIZ

http://www.designorate.com/trizmethod-problem-solving/

http://creatingminds.org/tools/triz/triz contradiction_analysis.htm

Altshuller, G., 2002, "40 principles; TRIZ keys to innovation (Vol. 1)." Technical Innovation Center, Inc., Worcester, MA.

34. C-Sketch

http://www.clemson.edu/ces/cedar/imi mag/0/06/13-C-Sketch.pdf . Accessed 06/2017.

Shah, J.J., Vargas-Hernandez, N., Summers, J.D., \& Kulkarni, S., 2001, "Collaborative Sketching (C-Sketch)-An idea generation technique for engineering design," The Journal of Creative Behavior. 35(3), pp. 168-198.

35. Concept generating matrix

Kumar, V., 2012, "101 design methods: A structured approach for driving innovation in your organization," John Wiley \& Sons, Hoboken. pp. 216-217

36. Ideation session

Kumar, V., 2012, "101 design methods: A structured approach for driving innovation in your organization," John Wiley \& Sons, Hoboken. pp. 212-214

37. SDI

https://www.mycoted.com/SDI

38. Laddering https://www.mycoted.com/Laddering 
39. Synectics

Pahl, G., and Beitz, W., 2007, "Engineering design: a systematic approach," 3. ed. Springer Science + Business Media. London.

40. Delphi Method http://creatingminds.org/tools/delphi.ht $\mathrm{m}$

Pahl, G., and Beitz, W., 2007,

"Engineering design: a systematic approach," 3. ed. Springer Science + Business Media. London.

41. SIT

Barak, M., 2004, "Systematic approaches for inventive thinking and problem-solving: Implications for engineering education," International Journal of Engineering Education, 20(4), 612-618.

Horowitz, R., 1999, "Creative problem solving in engineering design," PhD. diss., Tel-Aviv University.

42. Concrete stimuli

Herring, S.R., Jones, B.R., and Bailey, B.P., 2009, "Idea generation techniques among creative professionals," 42nd Hawaii International Conference on System Sciences.

43. Forced analogy

Herring, S.R., Jones, B.R., and Bailey, B.P., 2009, "Idea generation techniques among creative professionals," 42nd Hawaii International Conference on System Sciences.

http://members.optusnet.com.au/charle s57/Creative/Techniques/forced_analogy.ht $\mathrm{m}$

44. Gallery

Pahl, G., and Beitz, W., 2007

"Engineering design: a systematic approach," 3. ed. Springer Science + Business Media. London.

45. Passive searching

Herring, S.R., Jones, B.R., and Bailey, B.P., 2009, "Idea generation techniques among creative professionals," 42nd Hawaii International Conference on System Sciences.

46. Storyboarding

Herring, S.R., Jones, B.R., and Bailey, B.P., 2009, "Idea generation techniques among creative professionals," 42nd Hawaii International Conference on System Sciences. http://creatingminds.org/tools/storyboa rding.htm

VanGundy, A. B., 2005, "101 activities for teaching creativity and problem solving." Pfeiffer: San Francisco.

47. Braindrawing

http://creatingminds.org/tools/braindra wing.htm
48. Brain sketching

Martin, J., Bell, R., Farmer, E. and Henry, J., 2010, "Technique Library," Milton Keynes, UK: Open University. through: http://comscientia.com/training_course_exa $\mathrm{mples} / \mathrm{ctl} /$ pages/Brain\%20sketching.pdf

49. Nominal Group Technique http://creatingminds.org/tools/ngt.htm

50. Bodystorming Witthoft, S., \& Geehr, C. (n.d.). Bodystorming (Stanford d.school K12 Lab, Ed.). Retrieved February 17, 2020, from https://dschoolold.stanford.edu/groups/k12/wiki/48c54/Bo dystorming.html

51. Assumption Busting http://creatingminds.org/tools/assumpti on_busting.htm

52. Brainmapping http://creatingminds.org/tools/brainmap ping.htm

53. Challenge http://creatingminds.org/tools/challenge .htm

54. Essence htm http://creatingminds.org/tools/essence.

55. Forced Conflict http://creatingminds.org/tools/forced_c onflict.htm

56. How-How Diagram http://creatingminds.org/tools/how_ho w.htm

57. How to

http://creatingminds.org/tools/how_to.h tm

58. The Kipling method http://creatingminds.org/tools/kipling.ht $\mathrm{m}$

59. Lotus Blossom http://creatingminds.org/tools/lotus_blo ssom.htm

60. Chunking htm

http://creatingminds.org/tools/chunking

61. Mind-mapping

http://creatingminds.org/tools/mindmapping.htm

62. PSI

http://creatingminds.org/tools/psi.htm

63. Random Words

http://creatingminds.org/tools/random_ words.htm

64. Remembrance

http://creatingminds.org/tools/remembr ance.htm 
65. Rubber-ducking http://creatingminds.org/tools/rubber_d ucking.htm

66. Take a break http://creatingminds.org/tools/take_bre ak.htm

67. Pause

http://creatingminds.org/tools/pause.ht $\mathrm{m}$

68. Greetings cards https://www.mycoted.com/Greetings_C ards

69. Unfolding http://creatingminds.org/tools/unfolding .htm

70. Value Engineering http://creatingminds.org/tools/tools_ide ation.htm

Green, S., 1990, "The essentials of value engineering," Facilities, 8(10), pp. 15-17.

71. Wishing tm

http://creatingminds.org/tools/wishing.h

72. Concept metaphors and analogies

Kumar, V., 2012, "101 design methods: A structured approach for driving innovation in your organization," John Wiley \& Sons, Hoboken. pp. 218-220.

73. Ideation game

Kumar, V., 2012, "101 design methods: A structured approach for driving innovation in your organization," John Wiley \& Sons, Hoboken. pp. 212-214.

74. Word tree design by analogy

Linsey, J. S., Markman, A. B., and Wood, K. L. ,2012, "Design by analogy: a study of the WordTree Method for problem rerepresentation," Journal of Mechanical Design, 134(4), 041009.

75. Forward steps

Pahl, G., and Beitz, W., 2007, "Engineering design: a systematic approach," 3. ed. Springer Science + Business Media. London.

76. Backward steps

Pahl, G., and Beitz, W., 2007,

"Engineering design: a systematic approach," 3. ed. Springer Science + Business Media. London.

77. Mash-up

https://toolkits.dss.cloud/design/metho d-card/mash-up/

78. Sensorial

https://toolkits.dss.cloud/design/metho d-card/sensorial-2/

79. AOKI https://toolkits.dss.cloud/design/metho d-card/the-aoki-method-2/

80. Vip design

https://toolkits.dss.cloud/design/metho d-card/vip-design/

81. EED (empathic experience design)

Genco, N., Johnson, D., Hölttä-Otto, K., \& Seepersad, C. C., 2011, "A study of the effectiveness of empathic experience design as a creativity technique." In International Design Engineering Technical Conferences.

82. Bio-inspired ideation

Farel, R., and Yannou, B. ,2013, "Bioinspired ideation: Lessons from teaching design to engineering students." In DS 75-7: Proceedings of the 19th International Conference on Engineering Design (ICED13), Design for Harmonies, Vol. 7: Human Behaviour in Design, pp. 327-336, Seoul, Korea, 19-22.08.

83. Designlibs

Bauer, J. S., and Kientz, J. A., 2013, "Designlibs: A scenario-based design method for ideation," In Proceedings of the SIGCHI Conference on Human Factors in Computing Systems. pp. 1955-1958.

84. Cheatstorming

Faste, H., Rachmel, N., Essary, R., and Sheehan, E., 2013, "Brainstorm, Chainstorm, Cheatstorm, Tweetstorm: new ideation strategies for distributed $\mathrm{HCl}$ design," In Proceedings of the SIGCHI Conference on Human Factors in Computing Systems, pp. 1343-1352.

85. 6-3-5 Extended

Schroeer, B., Kain, A., and Lindemann, U., 2010, "Supporting creativity in conceptual design: Method 635-extended." In DS 60: Proceedings of DESIGN 2010, the 11th International Design Conference, Dubrovnik, Croatia.

86. Extreme Characters

Djajadiningrat, J. P., Gaver, W. W., and Fres, J. W., 2000, "Interaction relabelling and extreme characters: methods for exploring aesthetic interactions." In Proceedings of the 3rd conference on Designing interactive systems: processes, practices, methods, and techniques. pp. 66-71.

87. Fictional Inquiry

Dindler, C., and Iversen, O. S., 2007, "Fictional inquiry-design collaboration in a shared narrative space," CoDesign, 3(4), pp.213-234.

88. Future workshop

https://toolkits.dss.cloud/design/metho d-card/future-worksh 
Journal of Mechanical Design

\section{Appendix B}

The mechanism categories and methods categorized in each category.

\begin{tabular}{|c|c|}
\hline Mechanism & Methods coded in the category \\
\hline \multicolumn{2}{|c|}{ Implementation mechanisms } \\
\hline Team & $\begin{array}{l}\text { Reverse Brainstorming, Starbursting, Reversal, SCAMPER, Attribute listing, Morphological analysis, } \\
\text { Design Heuristics, Storyboarding, Assumption Busting, How-How Diagram, Lotus Blossom, Random } \\
\text { Words, Take a break, Pause, Wishing, AOKI, Bio-inspired ideation, Designlibs Future workshop, } \\
\text { Brainstorming, The Charette Procedure, Crawford slip writing method, Round-robin brainstorming, } \\
\text { Rolestorming, Role-play, Electronic Brainstorming, Brainwriting, 6- 3-5, Brainwriting Pool, Idea card } \\
\text { (pin card) method, Post-Up, Constrained brainwritin, Electronic, Brainwriting, The spreadsheet } \\
\text { technique, Interactive brainwriting, Brainwriting game, Matrix analysis, Six thinking hats, Po } \\
\text { (Provocation), Talking pictures, C-Sketc, Concept generating matri, Ideation session, SDI, Synectics, } \\
\text { Delphi Method, Gallery, Braindrawing, Brain sketching, Nominal Group Technique, Bodystormin, } \\
\text { Brainmapping, How to Chunking, Greetings cards, Unfolding, Concept metaphors and analogies, } \\
\text { Ideation game, Word tree design by analo, Sensorial, Vip design, 6-3-5 Extended, Fictional Inquiry }\end{array}$ \\
\hline Individual & $\begin{array}{l}\text { Reverse Brainstorming, Starbursting, Metaphorical thinking, Reversal, SCAMPER, Attribute listing, } \\
\text { Morphological analysis, The list of 100, Listing, Heuristic ideation technique (HIT), Design Heuristics, } \\
\text { TRIZ, Laddering, SIT, Concrete stimuli, Forced analogy, Passive searching, Storyboarding, } \\
\text { Assumption Busting, How-How Diagram, The Kipling method, Lotus Blossom, Mind-mapping, } \\
\text { Random Words, Remembrance, Rubber-ducking, Take a break, Pause, Value Engineering, Wishing, } \\
\text { AOKI, Bio-inspired ideation, Designlibs, Future workshop }\end{array}$ \\
\hline Given duration & $\begin{array}{l}\text { The Charette Procedure, Rolestorming, 6-3-5, Brainwriting game, Matrix analysis, C-Sketch, SDI, } \\
\text { Word tree design by analogy, Sensorial, 6-3-5 Extended, Mash-up }\end{array}$ \\
\hline Decide duration & $\begin{array}{l}\text { The Charette Procedure, Brainwriting game, C-Sketch, SDI, Reverse Brainstorming, Reversal, Take a } \\
\text { break, Brainstorming, Crawford slip writing method, Interactive brainwriting, Talking pictures, } \\
\text { Ideation session, Nominal Group Technique, Bodystorming }\end{array}$ \\
\hline $\begin{array}{l}\text { Open-ended } \\
\text { duration }\end{array}$ & $\begin{array}{l}\text { Reversal, Take a break, Crawford slip writing method, Rolestorming, Word tree design by analogy, } \\
\text { Challenge, PSI, Starbursting, SCAMPER, Attribute listing, Morphological analysis, Design Heuristics, } \\
\text { Storyboarding, Assumption Busting, How-How Diagram, Random Words, Pause, Wishing, Bio- } \\
\text { inspired ideation, Designlibs, Future workshop, Role-play, Electronic Brainstorming, Brainwriting, } \\
\text { Brainwriting Pool, Idea card (pin card) method, Post-Up, Constrained brainwriting, Electronic } \\
\text { Brainwriting, The spreadsheet technique, Six thinking hats, Po (Provocation), Concept generating } \\
\text { matrix, Synectics, Delphi Method, Gallery, Braindrawing, Brain sketching, Brainmapping, How to, } \\
\text { Chunking, Greetings cards, Unfolding, Concept metaphors and analogies, Vip design, Fictional } \\
\text { Inquiry, Metaphorical thinking, The list of 100, Listing, Heuristic ideation technique (HIT), TRIZ, } \\
\text { Laddering, SIT, Concrete stimuli, Forced analogy, Passive searching, The Kipling method, Mind- } \\
\text { mapping, Remembrance, Rubber- ducking, Value Engineering, Essence, Forced Conflict, Forward } \\
\text { steps, Backward steps, EED, Cheatstorming, Extreme Characters }\end{array}$ \\
\hline $\begin{array}{l}\text { Written } \\
\text { modality }\end{array}$ & $\begin{array}{l}\text { Laddering, TRIZ, Forced analogy, Essence, Random Words, Talking pictures, Braindrawing, PSI, } \\
\text { Concept generating matrix, Listing, Lotus Blossom, Idea card (pin card) method, Gallery, } \\
\text { Constrained brainwriting, Brainwriting Pool, 6-3-5, 6-3-5 Extended, Brainwriting, Wishing, } \\
\text { Brainmapping, Forward step, Attribute listing, SCAMPER, Ideation game, Starbursting, } \\
\text { Rolestorming, Ideation session, Sensorial, Future workshop, Matrix analysis, How-How Diagram, } \\
\text { Mind-mapping, The spreadsheet technique, Electronic Brainwriting, Reverse Brainstorming, The } \\
\text { Charette Procedure, Post-Up, Interactive brainwriting, Brainwriting game, AOKI, Round-robin } \\
\text { brainstorming, Electronic Brainstorming, Mash-up, SDI, Heuristic ideation technique (HIT), } \\
\text { Morphological analysis, Value Engineering, Delphi Method, The list of 100, Vip design, Nominal } \\
\text { Group Technique, Crawford slip writing method, Reversal, Assumption Busting }\end{array}$ \\
\hline Verbal modality & $\begin{array}{l}\text { Random Words, Talking pictures, Braindrawing, PSI, Wishing, SCAMPER, Ideation game, } \\
\text { Starbursting, Rolestorming, Ideation session,Matrix analysis, Reverse Brainstorming, The Charette } \\
\text { Procedure, Post-Up, Brainwriting game, AOKI, Round-robin brainstorming, SDI, Reversal, } \\
\text { Assumption Busting, Role-play, Synectics, Unfolding,How to, Six thinking hats, Po }\end{array}$ \\
\hline
\end{tabular}




\begin{tabular}{|c|c|}
\hline & (Provocation), Extreme Characters, Brainstorming, Rubber-ducking \\
\hline Physical modality & Role-play, Extreme Characters, Vip design, Concrete stimuli, Fictional Inquiry, Bodystorming \\
\hline Visual modality & $\begin{array}{l}\text { Braindrawing, Ideation game, Reverse, Brainstorming, Synectics, Gallery, 6-3-5 Extended, Forward } \\
\text { steps, Mind-mapping, Word tree design by analogy, Design Heuristics, C-Sketch, Brain sketching, } \\
\text { Storyboarding }\end{array}$ \\
\hline $\begin{array}{l}\text { Thought } \\
\text { modality }\end{array}$ & $\begin{array}{l}\text { Forward steps, Assumption Busting, How to, Ladderin, Essence, Value Engineering, Chunking, } \\
\text { Metaphorical thinking, Passive searching, Take a break, Challenge, The Kipling method, Pause, } \\
\text { Backward steps, Remembrance }\end{array}$ \\
\hline Facilitation & $\begin{array}{l}\text { Synectics, Reverse Brainstorming, Sensorial, Fictional Inquiry, Starbursting, Rolestorming, Ideation } \\
\text { session, Nominal Group Technique, Electronic Brainstorming, The list of 100, Brainstormin, } \\
\text { Ideation game, Delphi Method, Crawford slip writing method, AOKI, Brainwriting game, The } \\
\text { Charette Procedure, Round-robin brainstorming, Future Workshop, Greetings cards, Unfolding, } \\
\text { Pause, The spreadsheet technique, Braindrawing, Brain sketching, Talking pictures, Matrix analysis }\end{array}$ \\
\hline Special tool use & $\begin{array}{l}\text { Electronic Brainstorming, Brainwriting game, Word tree design by analogy, Design Heuristics, } \\
\text { Fictional Inquiry, Ideation game, Delphi Method, The spreadsheet technique, Talking pictures, } \\
\text { TRIZ, Electronic Brainwriting, Forced analogy, Passive searching }\end{array}$ \\
\hline \multicolumn{2}{|c|}{ Idea promoting mechanisms } \\
\hline Analogies & $\begin{array}{l}\text { Laddering, Concrete stimuli, Chunking, Word tree design by analogy, Design Heuristics, Concept } \\
\text { metaphors and analogies, Role-play, Bio-inspired ideation, Metaphorical thinking, Forced Conflict, } \\
\text { TRIZ, Forced analogy, Synectics, Unfolding, Essence }\end{array}$ \\
\hline Association & $\begin{array}{l}\text { Random Words, Laddering, Talking pictures, Greetings cards, Braindrawing, PSI, Concrete stimuli, } \\
\text { Concept generating matrix, Listing }\end{array}$ \\
\hline $\begin{array}{l}\text { Building on } \\
\text { others }\end{array}$ & $\begin{array}{l}\text { Lotus Blossom, The spreadsheet technique, Electronic Brainwriting, Reverse Brainstorming, } \\
\text { Brainstorming, Idea card (pin card) method, The Charette Procedure, Brain sketching, Gallery, } \\
\text { Constrained brainwriting, Post-Up, Designlibs, Brainwriting Pool, Interactive brainwriting, } \\
\text { Brainwriting gamel, C-Sketch, 6-3-5, 6-3-5 Extended, Brainwriting, AOKI, Round-robin } \\
\text { brainstorming, Chunking, Wishing, Brainmapping, Random Words }\end{array}$ \\
\hline Incubation & Passive searching, Pause, Rubber-ducking, Take a break \\
\hline Stimulation & $\begin{array}{l}\text { Lotus Blossom, Idea card (pin card) method, Gallery, Constrained brainwriting, Designlibs, } \\
\text { Brainwriting Pool, C-Sketch, 6-3-5, 6-3-5 Extended, Brainwriting, Chunking, Wishing, Brainmapping, } \\
\text { Random Words, Word tree design by analogy, Design Heuristics, Forward steps, Attribute listing, } \\
\text { Cheatstorming, SCAMPER, Concept metaphors and analogies, Laddering, Passive searching, Take a } \\
\text { break, Fictional Inquiry, Ideation game, Talking pictures, Starbursting, Rolestorming, Ideation } \\
\text { session, Sensorial, Future workshop, Greetings cards, Braindrawing, Matrix analysis, Challenge, PSI, } \\
\text { How to, EED, Role-play, Six thinking hats, How-How Diagra, Bio- inspired ideation, Po } \\
\text { (Provocation), Metaphorical thinking, Concrete stimuli, The Kipling method, Mind-mapping, Forced } \\
\text { Conflict, Extreme Characters, Bodystorming }\end{array}$ \\
\hline $\begin{array}{l}\text { Aiming at a high } \\
\text { amount of ideas }\end{array}$ & $\begin{array}{l}\text { Reverse Brainstorming, Starbursting, Storyboarding, Rolestorming, Ideation session, Electronic } \\
\text { Brainstorming, The list of 100, Brainstorming, Brainwriting game, Word tree design by analogy, Vip } \\
\text { design, Backward steps, C-Sketch, 6-3-5, 6-3-5 Extended, Brainwriting, Mash-up, Forward steps, } \\
\text { Design Heuristics, Idea card (pin card) method }\end{array}$ \\
\hline Classification & $\begin{array}{l}\text { Gallery, Ideation game, Delphi Method, Concept generating matrix, Mash-up, How-How Diagram, } \\
\text { Crawford slip writing method, Post-Up, Forward steps, AOKI, Sensorial }\end{array}$ \\
\hline $\begin{array}{l}\text { Combination \& } \\
\text { Modifications }\end{array}$ & $\begin{array}{l}\text { Electronic Brainstorming, Word tree design by analogy, Design Heuristics, The spreadsheet } \\
\text { technique, TRIZ, Electronic Brainwriting, Forced analogy, Reverse Brainstorming, Brainstorming, } \\
\text { Mash-up, Forward steps, Idea card (pin card) method, The Charette Procedure, Brain sketching, } \\
\text { Attribute listing, Gallery, Constrained brainwriting, Concept generating matrix, Post-Up, SDI, } \\
\text { Listing, Heuristic ideation technique (HIT), Designlibs, Cheatstorming, SCAMPER, Morphological } \\
\text { analysis, Brainwriting Pool, Concept metaphors and analogies, Laddering, SIT, Value Engineering, } \\
\text { Interactive brainwriting }\end{array}$ \\
\hline
\end{tabular}




\begin{tabular}{|c|c|}
\hline Evaluation & $\begin{array}{l}\text { Brainwriting game, SDI, Gallery, Listing, Heuristic ideation technique (HIT), Ideation game, Delphi } \\
\text { Method, The Charette Procedure, Round-robin brainstorming, Rolestorming, Designlibs, Future } \\
\text { workshop, Concept generating matrix, Greetings cards, Fictional Inquiry, Ideation session }\end{array}$ \\
\hline Framing & $\begin{array}{l}\text { Synectics, Reverse Brainstorming, Sensorial, Fictional Inquiry, Reversal, Word tree design by } \\
\text { analogy, Challenge, PSI, Starbursting, Attribute listing, Storyboarding, Assumption Busting, How to, } \\
\text { Chunking, Vip design, TRIZ, Remembrance, Rubber-ducking, Essence, Backward steps, EED }\end{array}$ \\
\hline Iterations & $\begin{array}{l}\text { Reversal, How-How Diagra, Bio-inspired ideation, Synectics, Delphi Method, Brainmapping, } \\
\text { Unfolding, The Charette Procedure, Brainwriting game, C-Sketch, SDI, Reverse Brainstorming, 6- 3- } \\
\text { 5, 6-3-5 Extended, Lotus Blossom, Round-robin brainstorming }\end{array}$ \\
\hline Selection & $\begin{array}{l}\text { Brainwriting game, SDI, Gallery, Listing, Heuristic ideation technique (HIT), Cheatstorming, Nominal } \\
\text { Group Technique, Mash-up, Ideation game }\end{array}$ \\
\hline $\begin{array}{l}\text { Suspend } \\
\text { judgment }\end{array}$ & $\begin{array}{l}\text { Gallery, Rolestorming, Ideation session, Nominal Group Technique, Synectics, C-Sketch, Reverse } \\
\text { Brainstorming, 6-3-5, 6-3-5 Extended, Wishing, Role-play, Electronic Brainstorming, Brainwriting, } \\
\text { Constrained brainwriting, Electronic Brainwriting, Six thinking hats, The list of 100, Brainstorming }\end{array}$ \\
\hline
\end{tabular}




\section{Appendix C}

Coding table of the mechanisms describing the mapping of mechanisms to the methods. "1" marks the presence of the mechanisms in the method instructions.

Overall frequency included in the end of the table.

\begin{tabular}{|c|c|c|c|c|c|c|c|c|c|c|c|c|c|c|c|c|c|c|c|c|c|c|c|c|c|c|}
\hline & 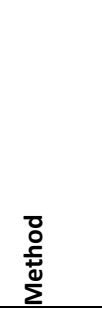 & 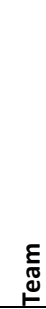 & 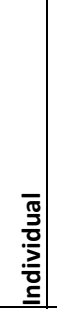 & 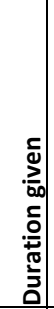 & 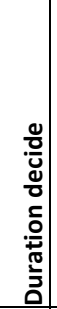 & 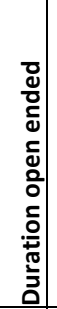 & 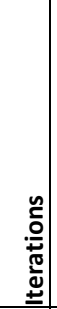 & 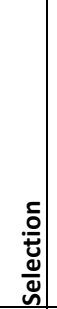 & 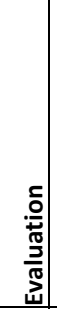 & 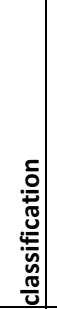 & 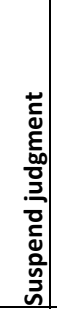 & 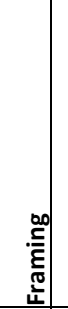 & 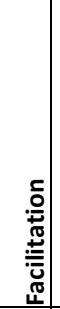 & 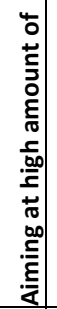 & 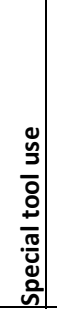 & 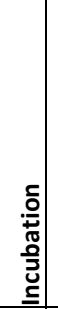 & 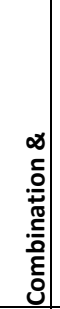 & 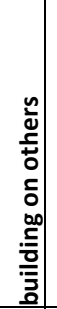 & 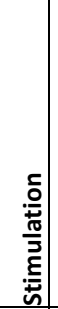 & 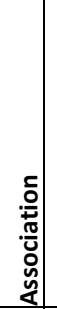 & 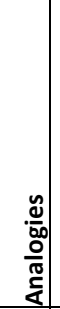 & 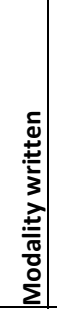 & 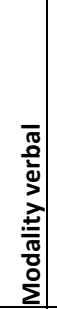 & $\begin{array}{l}\overline{0} \\
\frac{0}{n} \\
\frac{1}{0} \\
0 \\
\frac{2}{\pi} \\
\frac{\pi}{0} \\
\frac{0}{2}\end{array}$ & 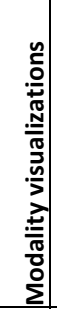 & 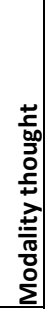 \\
\hline 1 & $\begin{array}{l}\text { Brains } \\
\text { tormi } \\
\text { ng }\end{array}$ & 1 & & & 1 & & & & & & 1 & & 1 & 1 & & & 1 & \begin{tabular}{l|l}
1 \\
\end{tabular} & & & & & \begin{tabular}{l|l|}
1 \\
\end{tabular} & & & \\
\hline 2 & $\begin{array}{l}\text { Rever } \\
\text { se } \\
\text { Brains } \\
\text { tormi } \\
\text { ng }\end{array}$ & 1 & 1 & & 1 & & 1 & & & & 1 & 1 & 1 & 1 & & & 1 & 1 & & & & 1 & 1 & & 1 & \\
\hline 3 & $\begin{array}{l}\text { Starb } \\
\text { urstin } \\
\mathrm{g}\end{array}$ & 1 & 1 & & & 1 & & & & & & 1 & 1 & 1 & & & & & 1 & & & 1 & 1 & & & \\
\hline 4 & $\begin{array}{l}\text { The } \\
\text { Chare } \\
\text { tte } \\
\text { Proce } \\
\text { dure }\end{array}$ & 1 & & 1 & 1 & & 1 & & 1 & & & & 1 & & & & 1 & 1 & & & & 1 & 1 & & & \\
\hline 5 & $\begin{array}{l}\text { Crawf } \\
\text { ord } \\
\text { slip } \\
\text { writin } \\
\text { g } \\
\text { meth } \\
\text { od }\end{array}$ & 1 & & & 1 & 1 & & & & 1 & & & 1 & & & & & & & & & 1 & & & & \\
\hline 6 & $\begin{array}{l}\text { Round } \\
\text {-robin } \\
\text { brains } \\
\text { tormi } \\
\text { ng }\end{array}$ & 1 & & & & & 1 & & 1 & & & & 1 & & & & & 1 & & & & 1 & 1 & & & \\
\hline 7 & $\begin{array}{l}\text { Rolest } \\
\text { ormin } \\
\mathrm{g}\end{array}$ & 1 & & 1 & & 1 & & & 1 & & 1 & & 1 & 1 & & & & & 1 & & & 1 & 1 & & & \\
\hline 8 & $\begin{array}{l}\text { Role- } \\
\text { play }\end{array}$ & 1 & & & & 1 & & & & & 1 & & & & & & & & 1 & & 1 & & 1 & 1 & & \\
\hline 9 & $\begin{array}{l}\text { Electr } \\
\text { onic } \\
\text { Brains } \\
\text { tormi } \\
\text { ng }\end{array}$ & 1 & & & & 1 & & & & & 1 & & 1 & 1 & 1 & & 1 & & & & & 1 & & & & \\
\hline $\begin{array}{l}1 \\
0\end{array}$ & $\begin{array}{l}\text { Brain } \\
\text { writin } \\
\text { g }\end{array}$ & 1 & & & & 1 & & & & & 1 & & & 1 & & & & 1 & 1 & & & 1 & & & & \\
\hline
\end{tabular}




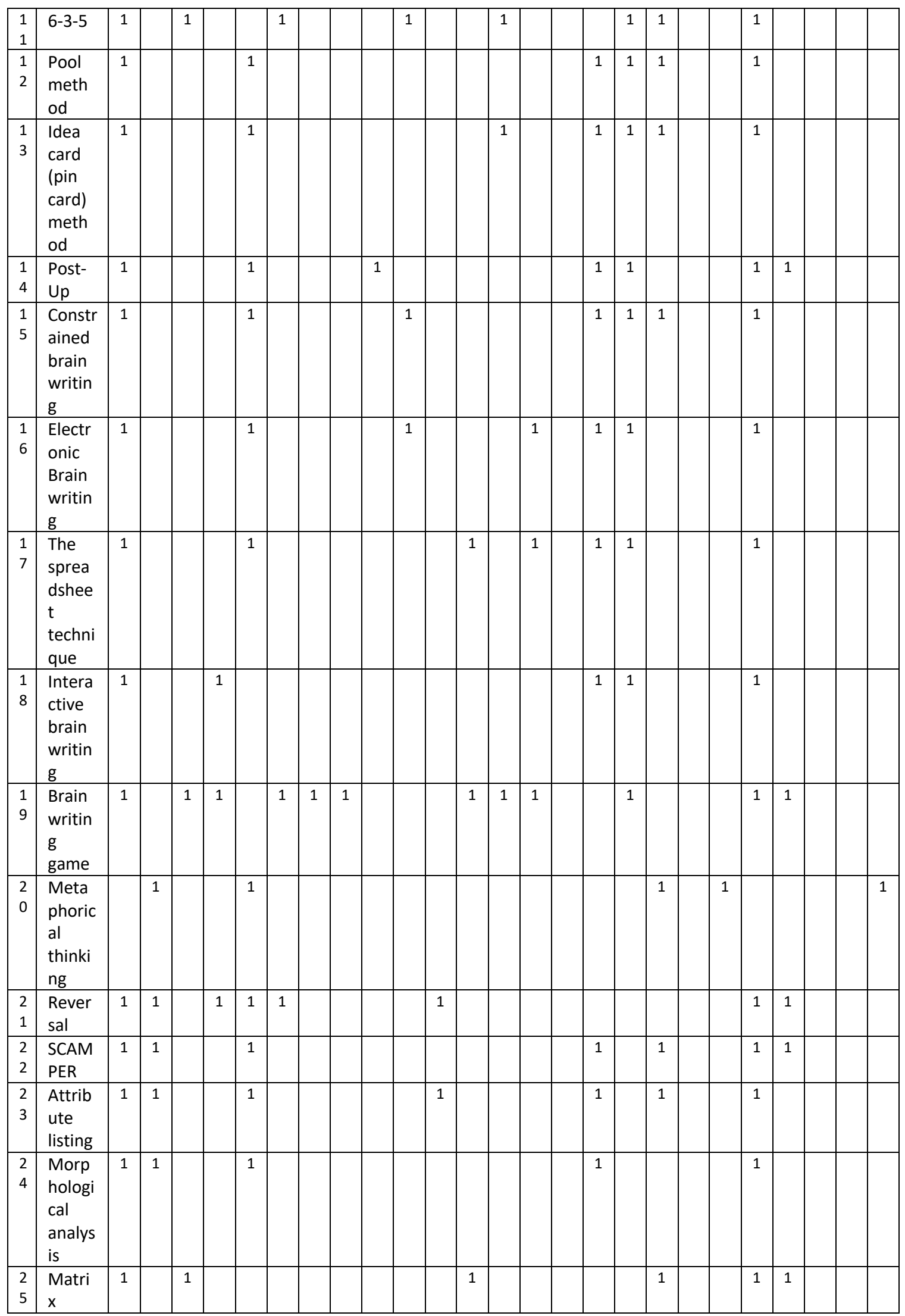




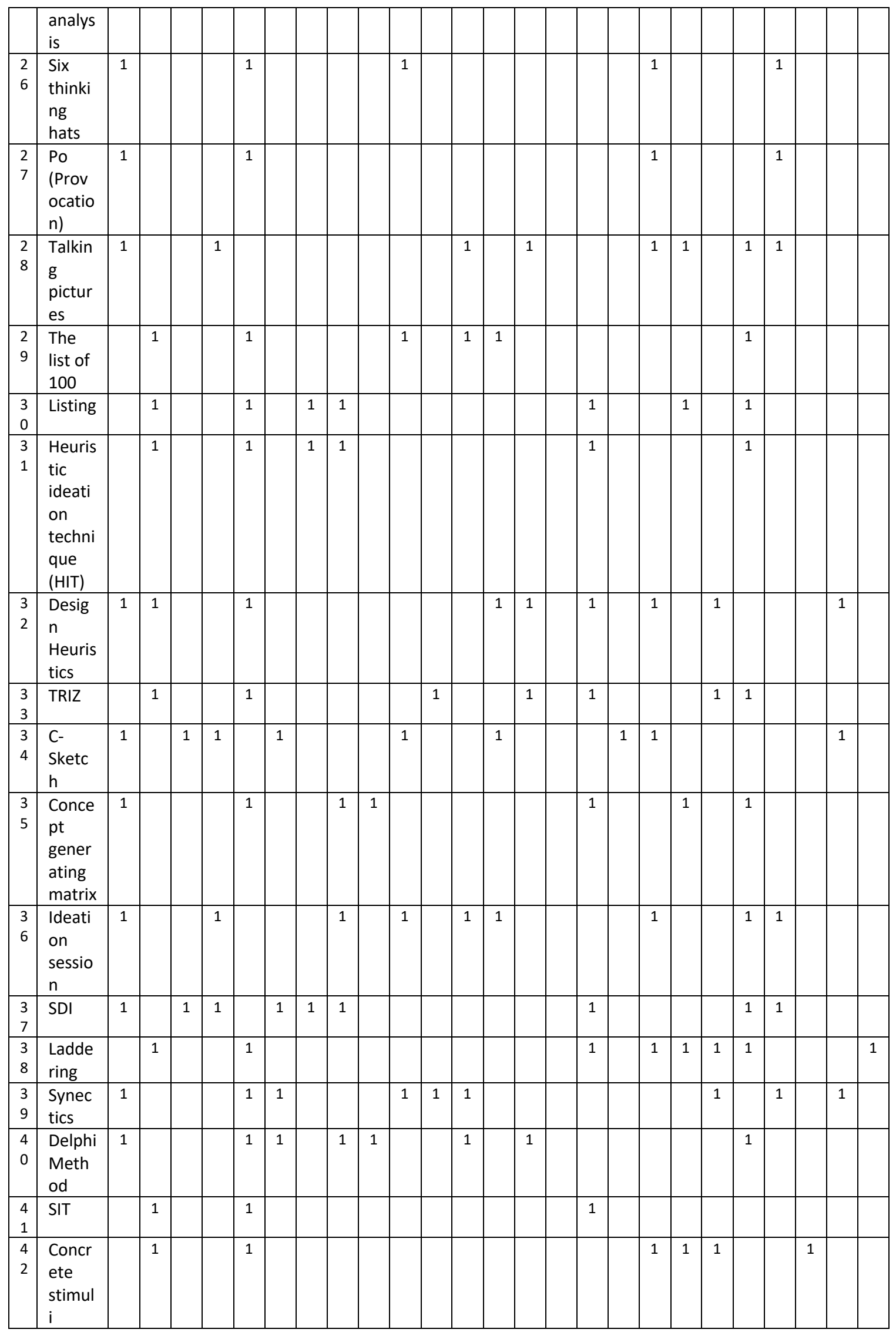




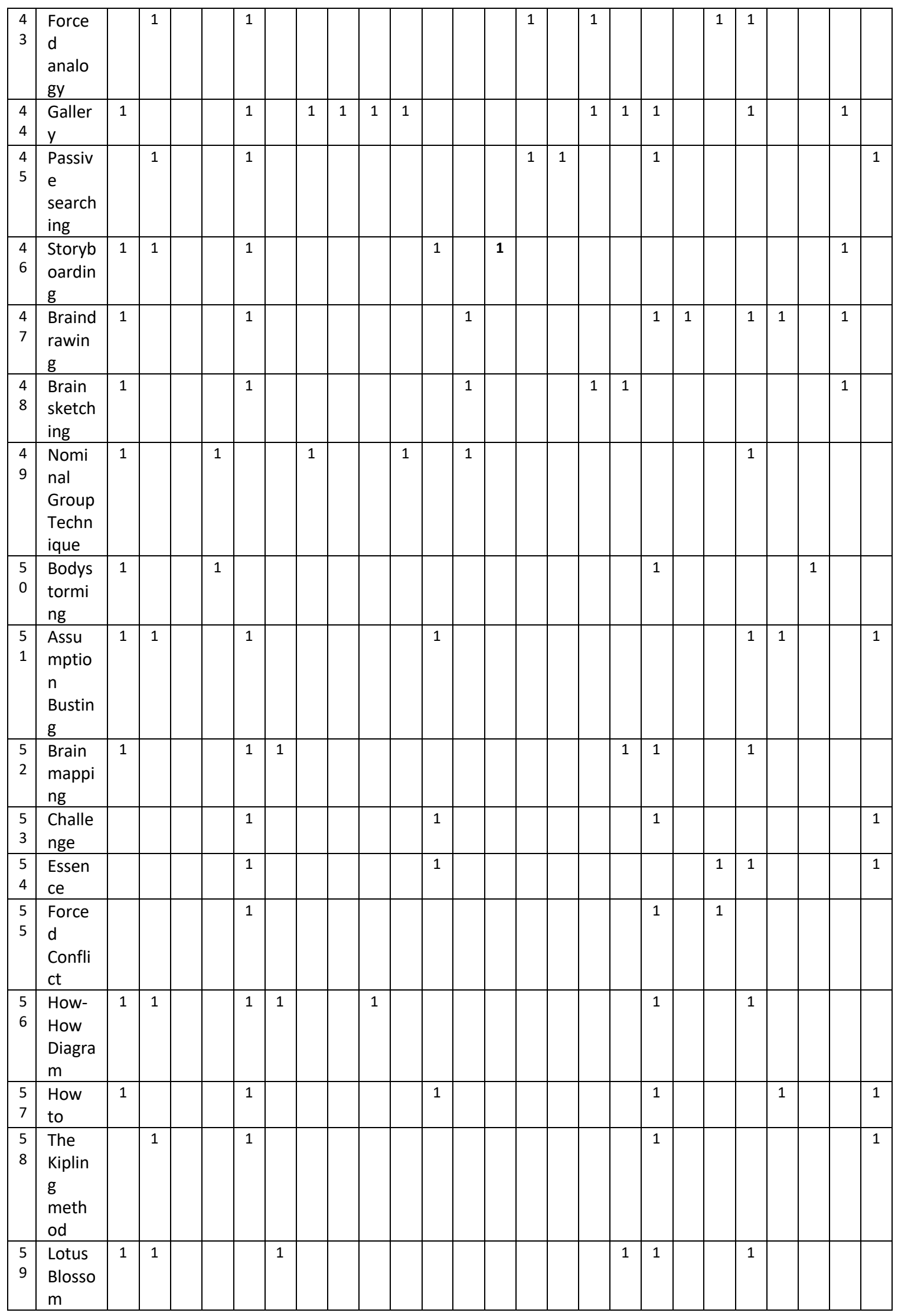




\begin{tabular}{|c|c|c|c|c|c|c|c|c|c|c|c|c|c|c|c|c|c|c|c|c|c|c|c|c|c|}
\hline $\begin{array}{l}6 \\
0\end{array}$ & $\begin{array}{l}\text { Chunk } \\
\text { ing }\end{array}$ & 1 & & & & 1 & & & & & & 1 & & & & & & 1 & 1 & & 1 & & & & 1 \\
\hline $\begin{array}{l}6 \\
1\end{array}$ & $\begin{array}{l}\text { Mind- } \\
\text { mappi } \\
\text { ng }\end{array}$ & & 1 & & & 1 & & & & & & & & & & & & & 1 & & & 1 & & 1 & \\
\hline $\begin{array}{l}6 \\
2\end{array}$ & PSI & & & & & 1 & & & & & & 1 & & & & & & & 1 & 1 & & 1 & 1 & & \\
\hline $\begin{array}{l}6 \\
3\end{array}$ & $\begin{array}{l}\text { Rando } \\
\mathrm{m} \\
\text { Word } \\
\mathrm{s}\end{array}$ & 1 & 1 & & & 1 & & & & & & & & & & & & 1 & 1 & 1 & & 1 & 1 & & \\
\hline $\begin{array}{l}6 \\
4\end{array}$ & $\begin{array}{l}\text { Reme } \\
\text { mbra } \\
\text { nce }\end{array}$ & & 1 & & & 1 & & & & & & 1 & & & & & & & & & & & & & 1 \\
\hline $\begin{array}{l}6 \\
5\end{array}$ & $\begin{array}{l}\text { Rubbe } \\
\text { r- } \\
\text { ducki } \\
\text { ng }\end{array}$ & & 1 & & & 1 & & & & & & 1 & & & & 1 & & & & & & & 1 & & \\
\hline $\begin{array}{l}6 \\
6\end{array}$ & $\begin{array}{l}\text { Take a } \\
\text { break }\end{array}$ & 1 & 1 & & 1 & 1 & & & & & & & & & & 1 & & & 1 & & & & & & 1 \\
\hline $\begin{array}{l}6 \\
7\end{array}$ & Pause & 1 & 1 & & & 1 & & & & & & & 1 & & & 1 & & & & & & & & & 1 \\
\hline $\begin{array}{l}6 \\
8\end{array}$ & $\begin{array}{l}\text { Greeti } \\
\text { ngs } \\
\text { cards }\end{array}$ & 1 & & & & 1 & & & 1 & & & & 1 & & & & & & 1 & 1 & & & & & \\
\hline $\begin{array}{l}6 \\
9\end{array}$ & $\begin{array}{l}\text { Unfol } \\
\text { ding }\end{array}$ & 1 & & & & 1 & 1 & & & & & & 1 & & & & & & & & 1 & & 1 & & \\
\hline $\begin{array}{l}7 \\
0\end{array}$ & $\begin{array}{l}\text { Value } \\
\text { Engin } \\
\text { eering }\end{array}$ & & 1 & & & 1 & & & & & & & & & & & 1 & & & & & 1 & & & 1 \\
\hline $\begin{array}{l}7 \\
1\end{array}$ & $\begin{array}{l}\text { Wishi } \\
\text { ng }\end{array}$ & 1 & 1 & & & 1 & & & & & 1 & & & & & & & 1 & 1 & & & 1 & 1 & & \\
\hline $\begin{array}{l}7 \\
2\end{array}$ & $\begin{array}{l}\text { Conce } \\
\text { pt } \\
\text { metap } \\
\text { hors } \\
\text { and } \\
\text { analo } \\
\text { gies }\end{array}$ & 1 & & & & 1 & & & & & & & & & & & 1 & & 1 & & 1 & & & & \\
\hline $\begin{array}{l}7 \\
3\end{array}$ & $\begin{array}{l}\text { Ideati } \\
\text { on } \\
\text { game }\end{array}$ & 1 & & & & & & 1 & 1 & 1 & & & 1 & & 1 & & & & 1 & & & 1 & 1 & 1 & \\
\hline $\begin{array}{l}7 \\
4\end{array}$ & $\begin{array}{l}\text { Word } \\
\text { tree } \\
\text { design } \\
\text { by } \\
\text { analo } \\
\text { gy }\end{array}$ & 1 & & 1 & & 1 & & & & & & 1 & & 1 & 1 & & 1 & & 1 & & 1 & & & 1 & \\
\hline $\begin{array}{l}7 \\
5\end{array}$ & $\begin{array}{l}\text { Forwa } \\
\text { rd } \\
\text { steps }\end{array}$ & & & & & 1 & & & & 1 & & & & 1 & & & 1 & & 1 & & & 1 & & 1 & 1 \\
\hline $\begin{array}{l}7 \\
6\end{array}$ & $\begin{array}{l}\text { Backw } \\
\text { ard } \\
\text { steps }\end{array}$ & & & & & 1 & & & & & & 1 & & 1 & & & & & & & & & & & 1 \\
\hline $\begin{array}{l}7 \\
7\end{array}$ & $\begin{array}{l}\text { Mash- } \\
\text { up }\end{array}$ & & & 1 & & & & 1 & & 1 & & & & 1 & & & 1 & & & & & 1 & & & \\
\hline $\begin{array}{l}7 \\
8\end{array}$ & $\begin{array}{l}\text { Senso } \\
\text { rial }\end{array}$ & 1 & & 1 & & & & & & 1 & & 1 & 1 & & & & & & 1 & & & 1 & & & \\
\hline
\end{tabular}


Journal of Mechanical Design

\begin{tabular}{|c|c|c|c|c|c|c|c|c|c|c|c|c|c|c|c|c|c|c|c|c|c|c|c|c|c|c|}
\hline $\begin{array}{l}7 \\
9\end{array}$ & AOKI & 1 & 1 & 1 & & & & & & 1 & & & 1 & & & & & 1 & & & & 1 & 1 & & & \\
\hline $\begin{array}{l}8 \\
0\end{array}$ & $\begin{array}{l}\text { Vip } \\
\text { design }\end{array}$ & 1 & & & & 1 & & & & & & 1 & & 1 & & & & & & & & 1 & & 1 & & \\
\hline $\begin{array}{l}8 \\
1 \\
\end{array}$ & EED & & & & & 1 & & & & & & 1 & & & & & & & 1 & & & & & & & \\
\hline $\begin{array}{l}8 \\
2\end{array}$ & $\begin{array}{l}\text { Bio- } \\
\text { inspir } \\
\text { ed } \\
\text { ideati } \\
\text { on }\end{array}$ & 1 & 1 & & & 1 & 1 & & & & & & & & & & & & 1 & & 1 & & & & & \\
\hline $\begin{array}{l}8 \\
3\end{array}$ & $\begin{array}{l}\text { Desig } \\
\text { nlibs }\end{array}$ & 1 & 1 & & & 1 & & & 1 & & & & & & & & 1 & 1 & 1 & & & & & & & \\
\hline $\begin{array}{l}8 \\
4\end{array}$ & $\begin{array}{l}\text { Cheat } \\
\text { stormi } \\
\text { ng }\end{array}$ & & & & & 1 & & 1 & & & & & & & & & 1 & & & & & & & & & \\
\hline $\begin{array}{l}8 \\
5\end{array}$ & $\begin{array}{l}\text { 6-3-5 } \\
\text { Exten } \\
\text { ded }\end{array}$ & 1 & & 1 & & & 1 & & & & 1 & & & 1 & & & & 1 & 1 & & & 1 & & & 1 & \\
\hline $\begin{array}{l}8 \\
6\end{array}$ & $\begin{array}{l}\text { Extre } \\
\text { me } \\
\text { Chara } \\
\text { cters }\end{array}$ & & & & & 1 & & & & & & & & & & & & & 1 & & & & 1 & 1 & & \\
\hline $\begin{array}{l}8 \\
7\end{array}$ & $\begin{array}{l}\text { Fictio } \\
\text { nal } \\
\text { Inquir } \\
y\end{array}$ & 1 & & & & 1 & & & 1 & & & 1 & 1 & & 1 & & & & 1 & & & & & 1 & & \\
\hline $\begin{array}{l}8 \\
8\end{array}$ & $\begin{array}{l}\text { Futur } \\
\text { e } \\
\text { Works } \\
\text { hop }\end{array}$ & 1 & 1 & & & 1 & & & 1 & & & & 1 & & & & & & 1 & & & 1 & & & & \\
\hline & Total & $\begin{array}{l}6 \\
3\end{array}$ & $\begin{array}{l}3 \\
4\end{array}$ & $\begin{array}{l}1 \\
2\end{array}$ & $\begin{array}{l}1 \\
4\end{array}$ & $\begin{array}{l}6 \\
8\end{array}$ & $\begin{array}{l}1 \\
6\end{array}$ & 9 & $\begin{array}{l}1 \\
6\end{array}$ & $\begin{array}{l}1 \\
1\end{array}$ & $\begin{array}{l}1 \\
8\end{array}$ & $\begin{array}{l}2 \\
1\end{array}$ & $\begin{array}{l}2 \\
7\end{array}$ & $\begin{array}{l}1 \\
9\end{array}$ & $\begin{array}{l}1 \\
3\end{array}$ & 4 & $\begin{array}{l}3 \\
2\end{array}$ & $\begin{array}{l}2 \\
5\end{array}$ & $\begin{array}{l}5 \\
0\end{array}$ & 9 & $\begin{array}{l}1 \\
5\end{array}$ & $\begin{array}{l}5 \\
4\end{array}$ & $\begin{array}{l}2 \\
9\end{array}$ & 6 & $\begin{array}{l}1 \\
3\end{array}$ & $\begin{array}{l}1 \\
5\end{array}$ \\
\hline & $\begin{array}{l}\text { Frequ } \\
\text { ency }\end{array}$ & $\begin{array}{l}7 \\
2 \\
\% \\
\end{array}$ & $\begin{array}{l}3 \\
9 \\
\% \\
\end{array}$ & $\begin{array}{l}1 \\
4 \\
\% \\
\end{array}$ & $\begin{array}{l}1 \\
6 \\
\% \\
\end{array}$ & $\begin{array}{l}7 \\
7 \\
\% \\
\end{array}$ & $\begin{array}{l}1 \\
8 \\
\% \\
\end{array}$ & \begin{tabular}{|l|}
1 \\
0 \\
$\%$ \\
\end{tabular} & $\begin{array}{l}1 \\
8 \\
\% \\
\end{array}$ & $\begin{array}{l}1 \\
3 \\
\% \\
\end{array}$ & $\begin{array}{l}2 \\
0 \\
\% \\
\end{array}$ & $\begin{array}{l}2 \\
4 \\
\% \\
\end{array}$ & $\begin{array}{l}3 \\
1 \\
\% \\
\end{array}$ & $\begin{array}{l}2 \\
2 \\
\% \\
\end{array}$ & $\begin{array}{l}1 \\
5 \\
\% \\
\end{array}$ & $\begin{array}{l}5 \\
\%\end{array}$ & $\begin{array}{l}3 \\
6 \\
\% \\
\end{array}$ & $\begin{array}{l}2 \\
8 \\
\% \\
\end{array}$ & $\begin{array}{l}5 \\
7 \\
\% \\
\end{array}$ & $\begin{array}{l}1 \\
0 \\
\%\end{array}$ & $\begin{array}{l}1 \\
7 \\
\% \\
\end{array}$ & $\begin{array}{l}6 \\
1 \\
\% \\
\end{array}$ & $\begin{array}{l}3 \\
3 \\
\% \\
\end{array}$ & $\begin{array}{l}7 \\
\%\end{array}$ & $\begin{array}{l}1 \\
5 \\
\% \\
\end{array}$ & $\begin{array}{l}1 \\
7 \\
\% \\
\end{array}$ \\
\hline
\end{tabular}

